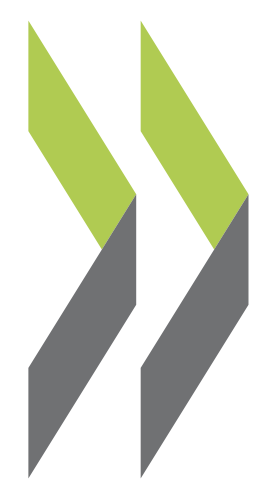

OECD Economics Department Working Papers No. 1548

Like it or not? The impact of online platforms on the productivity of incumbent service providers
Alberto Bailin Rivares, Peter Gal, Valentine Millot, Stéphane Sorbe 


\section{LIKE IT OR NOT? THE IMPACT OF ONLINE PLATFORMS ON THE PRODUCTIVITY OF INCUMBENT SERVICE PROVIDERS}

ECONOMICS DEPARTMENT WORKING PAPERS No. 1548

\section{By Alberto Bailin Rivares, Peter Gal, Valentine Millot and Stéphane Sorbe}

OECD Working Papers should not be reported as representing the official views of the OECD or of its member countries. The opinions expressed and arguments employed are those of the author(s).

Authorised for publication by Luiz de Mello, Director, Policy Studies Branch, Economics Department.

All Economics Department Working Papers are available at www.oecd.org/eco/workingpapers

JT03447476 
OECD Working Papers should not be reported as representing the official views of the OECD or of its member countries. The opinions expressed and arguments employed are those of the author(s).

Working Papers describe preliminary results or research in progress by the author(s) and are published to stimulate discussion on a broad range of issues on which the OECD works.

Comments on Working Papers are welcomed, and may be sent to OECD Economics Department, 2 rue André Pascal, 75775 Paris Cedex 16, France, or by e-mail to eco.contact@oecd.org.

All Economics Department Working Papers are available at www.oecd.org/eco/workingpapers

(C) OECD (2019)

You can copy, download or print OECD content for your own use, and you can include excerpts from OECD publications, databases and multimedia products in your own documents, presentations, blogs, websites and teaching materials, provided that suitable acknowledgment of OECD as source and copyright owner is given. All requests for commercial use and translation rights should be submitted to rights@,oecd.org 


\section{ABSTRACT/RÉSUMÉ \\ Like it or not? The impact of online platforms on the productivity of incumbent service providers}

This paper uses a novel empirical approach to assess if the development of online platforms affects the productivity of service firms. We build a proxy measure of platform use across four industries (hotels, restaurants, taxis and retail trade) and ten OECD countries using internet search data from Google Trends, which we link to firm-level data on productivity in these industries. We find that platform development supports the productivity of the average incumbent service firm and also stimulates labour reallocation towards more productive firms in these industries. This may notably reflect that platforms' user review and rating systems reduce information asymmetries between consumers and service providers, enhancing competition between providers. The effects depend on platform type. "Aggregator" platforms that connect incumbent service providers to consumers tend to push up the productivity of incumbents, while more disruptive platforms that enable new types of providers to compete with them (e.g. home sharing, ride hailing) have on average no significant effect on it. Consistent with this, we find that different platform types affect differently the profits, mark-ups, employment and wages of incumbent service firms. Finally, the productivity gains from platforms are lower when a platform is persistently dominant on its market, suggesting that the contestability of platform markets should be promoted.

JEL classification codes: D24, L13, L80, O33

Keywords: platforms; productivity; services; digital; competition; google trends; user rating.

\section{Liker ou non? L'impact des plateformes en ligne sur la productivité des fournisseurs de services existants}

Cet article utilise une nouvelle approche empirique pour évaluer si le développement des plateformes en ligne affecte la productivité des entreprises de services. Nous construisons une mesure approchée de l'utilisation des plateformes dans quatre secteurs (hôtels, restaurants, taxis et commerce de détail) et dix pays de l'OCDE, à l'aide des données de recherche Internet de Google Trends, que nous lions à des données d'entreprises sur la productivité dans ces secteurs. Nous constatons que le développement des plateformes soutient la productivité moyenne des entreprises de service existantes et stimule également la réallocation de la main-d'œuvre vers les entreprises les plus productives dans ces secteurs. Cela peut notamment refléter le fait que les systèmes de revue et d'évaluation par les utilisateurs disponibles sur les plateformes réduisent les asymétries d'information entre consommateurs et fournisseurs de services, renforçant ainsi la concurrence entre les fournisseurs. Les effets dépendent du type de plateforme considéré. Les plates-formes dites agrégatrices, qui relient les fournisseurs de services existants aux consommateurs, tendent à accroître la productivité, des premiers, tandis que les plates-formes plus disruptives qui permettent à de nouveaux types de fournisseurs de concurrencer les fournisseurs traditionnels (par exemple, partage de logement, voitures de tourisme avec chauffeur) n'ont en moyenne pas d'effet significatif sur elle. De manière cohérente, nous constatons que différents types de plateformes affectent différemment les profits, les marges, l'emploi et les salaires des entreprises de services. Enfin, les gains de productivité réalisés par les plateformes sont moins importants lorsqu'une plate-forme domine son marché de manière persistante, ce qui suggère que la contestabilité des marchés de plateformes doit être encouragée.

Code de classification JEL : D24, L13, L80, O33

Mots-clés : plateformes; productivité; services; numérique; concurrence; google trends; évaluation des utilisateurs. 


\section{Table of contents}

\section{LIKE IT OR NOT? THE IMPACT OF ONLINE PLATFORMS ON THE PRODUCTIVITY OF INCUMBENT SERVICE PROVIDERS \\ 6}

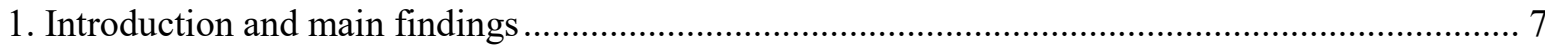

2. Platforms, productivity and policies: channels and existing evidence........................................ 11

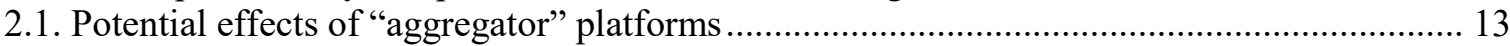

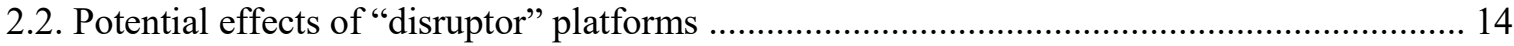

2.3. Platforms' effects may depend on the intensity of competition among them .......................... 15

2.4. Other policies can influence the economic effects of platforms ............................................ 17

3. Empirical strategy to assess the economic effects of platform development.................................. 17

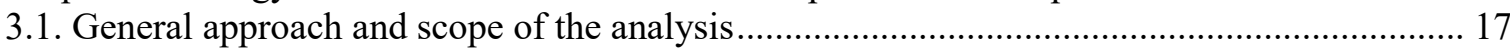

3.2. Building a proxy measure of platform use based on Google Trends data............................... 19

3.3. Firm-level data on the productivity of existing service providers........................................ 22

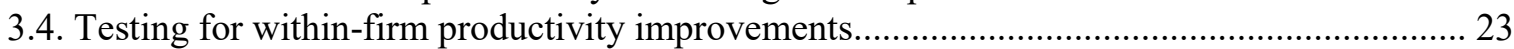

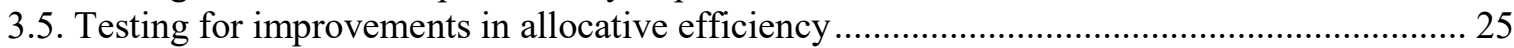

3.6. Assessing the effect of policies on platform-productivity links .............................................. 26

3.7. Effect of platforms on other characteristics of service providers ............................................. 28

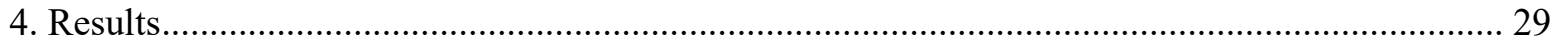

4.1. Platforms increase the average productivity of service providers ......................................... 29

4.2. Platform use and labour reallocation among existing service providers .................................. 31

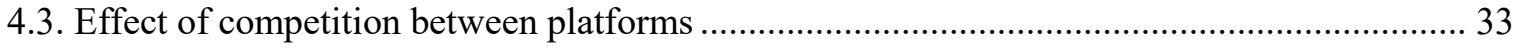

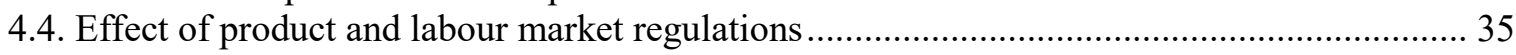

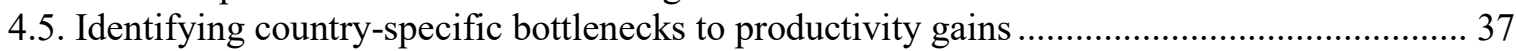

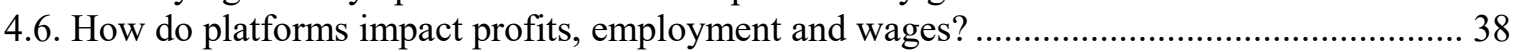

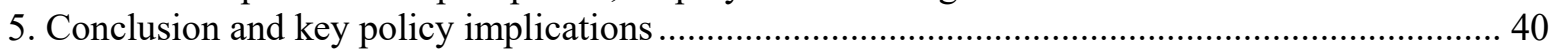

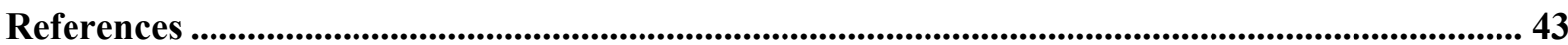

Annex A. Additional information on the platform indicator and descriptive statistics................. 48

Annex B. Detailed regression results and robustness checks ..............................................................51

\section{Tables}

Table 1. Main platforms covered in the analysis

Table 2. Effect of online platforms on the productivity of existing service providers, baseline results.

Table 3. Effect of online platforms on the productivity of existing service providers, sector-specific

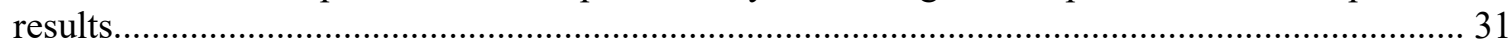

Table 4. Effect of online platforms on allocative efficiency, baseline results..................................... 32

Table 5. Effect of online platforms on allocative efficiency, sector-specific results ............................ 33

Table 6. Effect of online platforms on the productivity of existing service providers, effect of

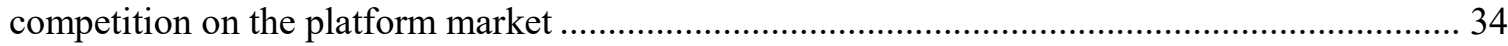

Table 7. Effect of online platforms on the productivity of existing service providers, effect of

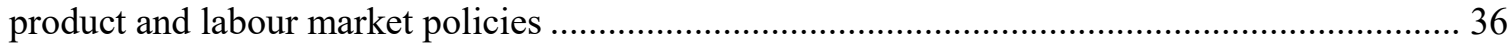

Table 8. Structural and policy factors influencing the impact of platforms on the productivity of existing service providers. 38 
Table 9. The impact of platform use on profitability and labour 39

Table 10. The impact of platform use on profitability and labour by sectors ....................................... 40

Table A.1. Detailed list of platforms included in the analysis

Table A.2. Descriptive statistics on the final firm-level sample

Table B.1. Effect of online platforms on the productivity of existing service providers, alternative specifications

Table B.2. Effect of online platforms on the productivity of existing service providers, robustness to different time lags.....

Table B.3. Effect of online platforms on the productivity of existing service providers, robustness to controlling for overall demand in each country, industry and year

Table B.4. Effect of online platforms on the productivity of existing service providers, alternative productivity measures.

Table B.5. Effect of online platforms on the productivity of existing service providers, restricting the sample to five countries

Table B.6. Effect of online platforms on the productivity of existing service providers, detailed results by sector

Table B.7. Effect of online platforms on allocative efficiency, alternative productivity measures ...... 56

Table B.8. Effect of online platforms on allocative efficiency, restricting the sample to five countries

Table B.9. Effect of online platforms on allocative efficiency, detailed results by sector ................... 58

Table B.10. Effect of online platforms on the productivity of existing service providers, effect of competition on the platform market, alternative concentration variables

\section{Figures}

Figure 1. Online platforms have developed rapidly over the past decade

Figure 2. Effects of online platforms on the productivity of service providers.................................... 12

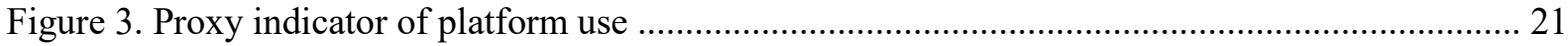

Figure 4. The contestability of platform markets varies across industries ........................................... 27

Figure 5. Impact of platform development on the productivity of service providers ............................ 30

Figure 6. Intensity of labour reallocation to the more productive firms ............................................... 32

Figure 7. More competition between platforms leads to higher productivity benefits ......................... 35

Figure 8. Stricter product and labour market regulations reduce the productivity benefits from

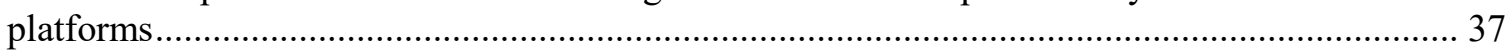

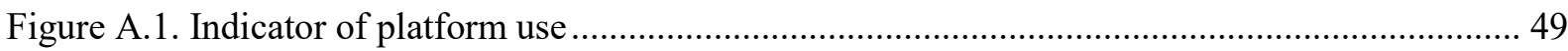

\section{Boxes}

Box 1. How can platforms make consumer reviews and ratings more trustworthy? .......................... 15

Box 2. Google Trends data: main characteristics and use in empirical analysis .................................. 20

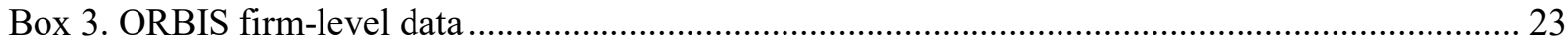




\title{
LIKE IT OR NOT? THE IMPACT OF ONLINE PLATFORMS ON THE PRODUCTIVITY OF INCUMBENT SERVICE PROVIDERS
}

\author{
By Alberto Bailin Rivares, Peter Gal, Valentine Millot and Stéphane Sorbe ${ }^{1}$
}

\section{EXECUTIVE SUMMARY}

The development of online platforms has profoundly transformed the functioning of many service industries over the past decade. Platforms have taken a central role as intermediaries between existing service providers and consumers, while also enabling the emergence of new types of service providers.

However, little is known about the economic effects of platform development on service firms. For example, does the rising availability of consumer reviews and ratings enhance competition between service providers and stimulate their productivity? How does the emergence of new types of providers affect incumbents? Is competition between platforms efficiency-enhancing or not? Understanding this better is important for designing policies related to platforms and service industries.

To contribute to answering these questions, this paper builds a novel proxy indicator of platform development across four service industries (hotels, restaurants, taxis and retail trade) and ten OECD countries over 2004-17, using internet search data from Google Trends. This indicator is matched to firm-level data on the productivity of incumbent firms in these industries to assess how platform development affects them.

Overall, platform development is found to support the productivity of the average incumbent service firm and also stimulate labour reallocation towards the most productive of them.

The effects depend crucially on the type of platform considered. "Aggregator" platforms that connect existing service providers to consumers (e.g. Booking.com, TheFork) have tended to push up productivity, profits and employment of existing service firms. In contrast, more disruptive platforms that enable new types of providers to compete with existing ones (e.g. Uber, Airbnb) are not found to have had a significant effect on the productivity of existing providers, but tended to reduce their mark-ups, employment and wages. The productivity of these new providers is difficult to assess for conceptual and data reasons.

The effects of platforms depend heavily on structural and policy factors, with first-order implications for policies:

${ }^{1}$ All four authors were in the OECD Economics Department at the time of this work. The authors would like to thank Sebastian Barnes, Laurence Boone, Luiz de Mello, Alain de Serres, Jens Hoj, Giuseppe Nicoletti, Yehuda Porath and Cyrille Schwellnus (all from the OECD Economics Department), Jeremy West (OECD Science, Technology and Innovation Directorate) and James Mancini (OECD Directorate for Financial and Enterprise Affairs) for their valuable comments. The authors would also like to thank Sarah Michelson (also from the OECD Economics Department) for excellent editorial support. 
- Platform markets are often extremely concentrated as they feature strong multi-sided network effects. However, the productivity gains induced by "aggregator" platforms are found to be reduced when a platform is persistently dominant on its market, suggesting that contestability of platform markets should be promoted, including by reducing switching costs between platforms and via strict enforcement of competition policy tools.

- Strict product and labour market regulations are found to hinder the productivity of incumbent service firms when platforms develop, possibly because they reduce firms' ability to adjust to a rapidly changing economic environment. This calls for reassessing regulations in the light of platform development. Certain rules that have become obsolete or unduly protect incumbents should be eliminated, while the new types of service providers enabled by platforms should gradually be submitted to tax and regulatory rules equivalent to those in activities they compete with, so as to ensure a level playing field.

\section{Introduction and main findings}

1. The rapid development of online platforms is transforming many service industries across OECD countries. For example, consumers searching for hotels increasingly rely on reviews and ratings provided by platforms (e.g. Booking.com, TripAdvisor). At the same time, hotels face rising competition from new accommodation providers enabled by platforms (e.g. Airbnb). Over the past decade, platforms have developed in many other service industries, including personal transport, restaurants, retail trade, entertainment and personal services. Business-to-business (B2B) platforms, while much less widespread than business-to-consumer (B2C) ones, are also gaining ground.

2. The development of online platforms creates both economic opportunities and challenges. On the one hand, platforms offer large potential benefits for consumers, which explains their rising popularity. Their innovative business models have enabled the emergence of new services (e.g. ride-hailing services, home sharing) while also facilitating transactions with established service providers (e.g. hotels, restaurants) thanks notably to the widespread use of consumer reviews and ratings. Better-rated providers attract more demand, giving all providers strong incentives to increase service quality and reduce prices. On the other hand, the development of platforms poses potential competition issues arising from winner-takes-all dynamics at the level of platforms themselves, since platform activities are characterised by very strong network effects. Platform development also opens questions related to the regulation of the new activities they enable, the way firms compete on platforms (e.g. is there a risk of so-called algorithmic collusion in price setting) and more broadly to labour relations, taxation and data protection.

3. After more than a decade of growth, online platforms have become central players in several industries, although the exact timing of their take-off differs across countries and industries (Figure 1). The coming years are therefore a key moment to define or adjust the policies regarding platforms and the industries in which they operate. This is a difficult undertaking because of platforms' very diverse and fast-changing business models and of the potential trade-offs involved. For example, the fact that an innovative platform obtains a dominant position in an industry might be efficiency-enhancing in the short term thanks to positive network effects (e.g. more data and users may allow it to improve its algorithms 
and offer better services) but detrimental in the longer run if entrenched dominance undermines competitive pressures and innovation incentives.

Figure 1. Online platforms have developed rapidly over the past decade

Panel A: Platform development by country

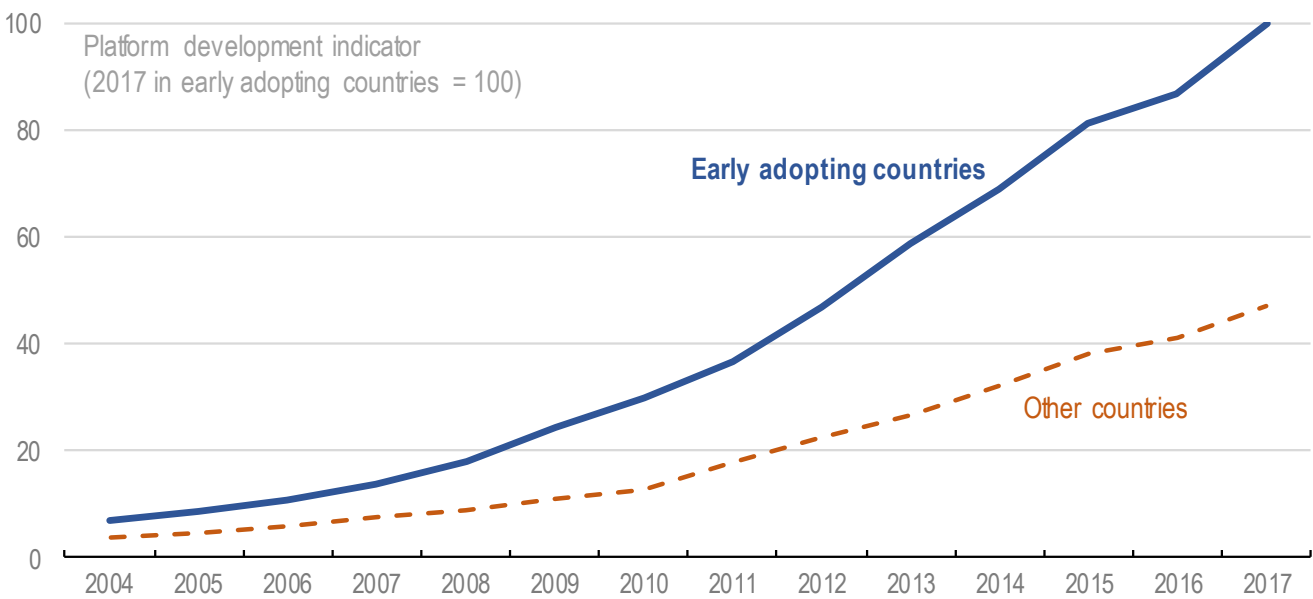

Panel B: Platform development by industry

Hotels

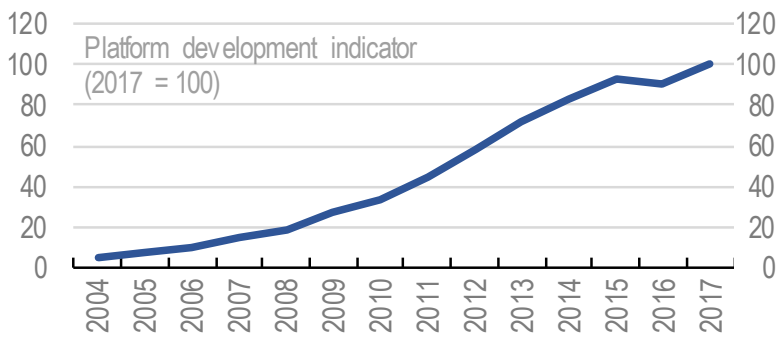

Taxi

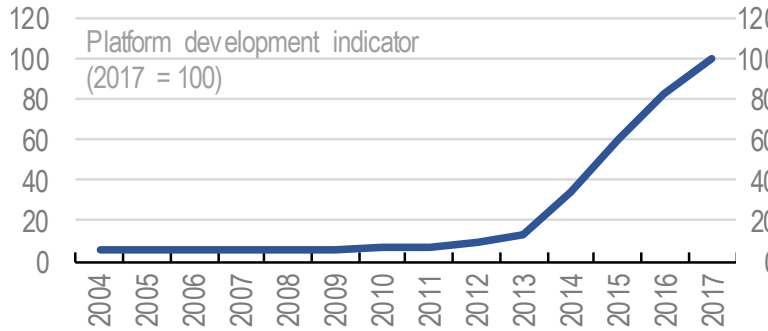

\section{Restaurants}

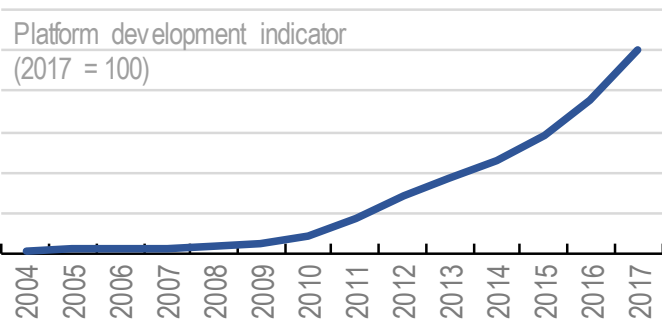

Retail subsectors

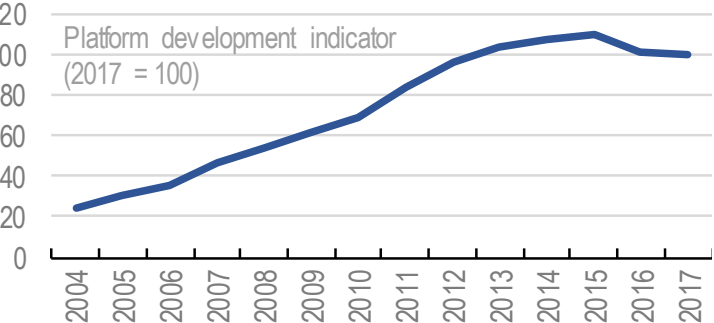

Note: Popularity of the largest relevant platforms in each industry, based on the number of Google searches for each platform (as a share of total Google searches in each country). Panel A is the unweighted average of the four selected industries (hotels, restaurants, taxis and retail trade). "Early adopting countries" is the unweighted average of the five countries in the sample with above-average platform development (France, Italy, Spain, United Kingdom and United States). "Other countries" is the unweighted average of the five other countries in the sample (Belgium, Germany, Hungary, Poland and Sweden). Panel B is the unweighted average of the 10 selected OECD countries. Retail trade is the simple average of five subsectors (retail trade of books, shoes, cosmetics and perfumes, watches and jewellery, and toys).

Source: OECD calculations based on Google Trends data. 
4. This paper contributes to informing this debate by assessing one particular aspect of the economic implications of online platform development, which is their effect on the productivity of incumbent service providers (i.e. providers whose existence predates platform development). ${ }^{2}$ The focus is on platforms that connect consumers to service providers in four services industries where platforms have gained an important size in many OECD countries: hotels, restaurants, taxi services and retail trade. These sectors constitute a significant part of services activities, employing about a quarter of workers in the nonfarm business sector. Our findings may also be relevant for other industries not covered in the analysis because platform development has been more recent or would be more difficult to map to the relevant service providers with the available data (e.g. entertainment, air transport, bank and insurance services, personal services).

5. This paper builds an innovative proxy measure of platforms' development based on their popularity as keywords in the Google search engine. This measure is constructed by summing - within each country, industry and year - the share of Google searches including the name of a selection of more than 50 relevant platforms. This proxy measure is unique in its ability to identify platform take-up across countries and industries in a systematic way, as it overcomes the issue that many platforms operating at a global level do not report detailed accounts by country (OECD, 2018 $\left.{ }_{[1]}\right)$. These data on platform development are then mapped to firm-level data from the ORBIS database on the productivity of service providers in these four industries across ten OECD countries. ${ }^{3}$ The activities considered correspond to a very detailed level of the industry classification (4digit level in the NACE Rev 2. classification) and a crucial advantage of ORBIS is to enable mapping at this level, while most industry-level datasets would only enable a much less precise mapping (1-digit or 2-digit level).

6. The findings suggest that platform development tends to stimulate the productivity of incumbent service providers. Over 2011-17, the estimated multifactor productivity gain for the average service provider in the industries considered was about 2.5 percent (1 percent) in sample countries with relatively high (low) platform development. In addition to this within-firm effect, platform development is found to allow more productive service providers to grow faster than less productive ones, which also supports aggregate productivity through an efficiency-enhancing reallocation of resources. As a result, while the strength of this reallocation has generally declined across OECD economies over the past decade, the countries and industries with the strongest platform development have kept on average a roughly constant reallocation intensity. Both the results on within-firm productivity and reallocation hold individually for most of the service industries included in the analysis and are also robust to using alternative specifications and productivity measures (labour productivity and various measures of multi-factor productivity).

7. Different types of platforms have had different effects on productivity. "Aggregator" platforms focusing on reviewing and rating existing service providers (e.g. Booking.com, Yelp) had a clear positive effect on the productivity of incumbents, both

\footnotetext{
2 The productivity of the new types of providers enabled by platforms (e.g. Uber drivers, Airbnb hosts) and of platforms themselves (in their role as intermediaries, sometimes replacing other intermediaries such as travel agencies) is not covered, as it is difficult to assess it systematically due to conceptual and data limitations about measuring the output and inputs (labour and capital) of these firms and self-employed individuals. See Section 2 for more details.

${ }^{3}$ The set of countries is restricted to those that have a relatively good coverage in the ORBIS firmlevel database and large economies with well-known platforms.
} 
within the average firm and through efficiency-enhancing reallocation. This suggests that ratings and reviews enhance competitive pressures among providers and also orient more demand toward better-rated (and presumably more productive) providers. In contrast, "disruptor" platforms that enable the emergence of new types of providers competing to some extent with existing ones (e.g. Uber, Airbnb) had no significant effect on the productivity of existing providers. Their effect on aggregate productivity therefore depends on whether these new types of providers themselves (e.g. home-sharing or ride-hailing services) are more or less productive than existing ones (e.g. hotels and taxis) which is difficult to assess systematically across countries and sectors both for conceptual reasons and due to data limitations. Overall, while this paper sheds light on the effect of platform development on the productivity of certain firms (incumbents in selected sectors and countries), the aggregate effect of platform development on economy-wide productivity remains uncertain.

8. In a second step, the paper explores how policies can affect the links between platform development and productivity. Productivity gains among service firms are found to be significantly weaker when a single platform is dominating the platform market in an industry (which is defined as a market share above the median in the sample, which is $64 \%$ ) and when this domination is persistent in time. This suggests that stiffer competition among platforms pushes them to improve their services (e.g. by investing into making ratings and reviews more trustworthy) which ultimately supports the productivity of service providers. Therefore, policies should aim at promoting competition between platforms, including by ensuring that platform markets remain contestable even when network effects are very strong. This calls for strictly enforcing competition policy tools and reducing switching costs between platforms (e.g. through enhanced data portability, facilitated "multi-homing" between platforms and stricter rules on "best-price" clauses).

9. The productivity gains associated to platform development are found to be reduced in presence of strict product and labour market regulations (e.g. complex administrative procedures, strict rules on the use of temporary work). A possible interpretation is that these regulations hinder the ability of service firms to adjust and reorganise themselves when faced by the important demand changes induced by platform development. More broadly, the development of platforms warrants reassessing certain regulations. For example, some regulations were meant to address information asymmetries between service providers and consumers (e.g. occupational licensing, quality standards) and may in some cases have become obsolete as platforms offer more efficient ways to address these asymmetries. In addition, new types of service providers enabled by platforms often face a lighter regulatory and tax environment than incumbents, which is one of the likely drivers of their development. While offering new activities a temporary window to experiment in a controlled environment (e.g. with "sandbox" policies) can stimulate innovation, these activities should gradually be submitted to regulations and taxes equivalent to the activities they compete with, so as to ensure a level playing field.

10. Finally, the paper provides initial evidence on the effect of platform development on other characteristics of service providers, including mark-ups, profits, employment and wages, to shed light on how these productivity gains are achieved and how they are used (e.g. to increase wages or profits). The productivity gains enabled by "aggregator" platforms are found to translate into slightly higher mark-ups, profits and employment, with no significant effect on wages per employee. In contrast, the development of "disruptor" platforms tends to reduce the mark-ups, employment and wages of incumbents, consistent with the idea that new types of providers compete with them. The exact size of these effects and mechanisms underlying them should be further investigated. In turn, the question of 
whether they represent a positive development (e.g. if incumbents were previously sheltered from competition by overly protective regulation) or a negative one (e.g. if new providers' only comparative advantage is the lighter tax and regulatory burden) should be assessed on a case-by-case basis.

\section{Platforms, productivity and policies: channels and existing evidence}

11. Online platforms can be defined as digital services that facilitate interactions between two or more distinct but interdependent sets of users (whether firms or individuals) who interact through the service via the Internet $($ OECD, 2019 $[2]){ }^{4}$ Platforms have very diverse activities, characteristics and business models. This paper only focuses on platforms whose primary activity is to connect service providers to consumers, either in replacement of existing intermediaries (e.g. travel agencies) or not (e.g. as a substitute to direct booking with a hotel).

12. Following Sorbe et al. (2018[3]), it is useful for analytical purposes to distinguish between two types of platforms: (i) platforms operating as "aggregators", which link consumers to existing service providers (e.g. Booking.com, Yelp) for example by providing searching tools, review and rating systems and sometimes booking facilities, and (ii) platforms that primarily link consumers to new types of service providers, whose activity is enabled by the innovative business model of the platform (e.g. Uber, Airbnb). These platforms tend to be more disruptive for incumbent service providers and are therefore called "disruptors" in this paper. ${ }^{5}$ They share many characteristics with aggregator platforms, for example the use of review and rating systems, but affect productivity in different ways. As discussed below, the main effect of "disruptor" platforms on incumbents is essentially a competition shock provoked by the entry of new providers that can compete with them. In contrast, the effect of "aggregator" platforms is more complex and involves several channels, mixing competition and technology shocks (Figure 2).

\footnotetext{
${ }^{4}$ More specifically, online platforms have a number of common economic characteristics, including positive direct and indirect network effects, cross-subsidisation, scale without mass, potentially global reach, panoramic scope, generation and use of user data, disruptive innovation, switching costs and, in some markets, winner-take-all or winner-take-most tendencies (OECD, 2019 $\left.{ }_{[2]}\right)$.

${ }^{5}$ Certain platforms engage in both types of activities. For example, Amazon can be considered as an "aggregator" platform with its Marketplace activity, which connects (generally existing) retailers to consumers, but it is also a new provider of retail services via its own-account e-commerce activity. In the case of Amazon, both activities have roughly the same size and Amazon is therefore included in both platform types in the empirical analysis. In other cases, one activity is largely dominating the other over the sample period, in which case the platform is only classified in one category.
} 
Figure 2. Effects of online platforms on the productivity of service providers

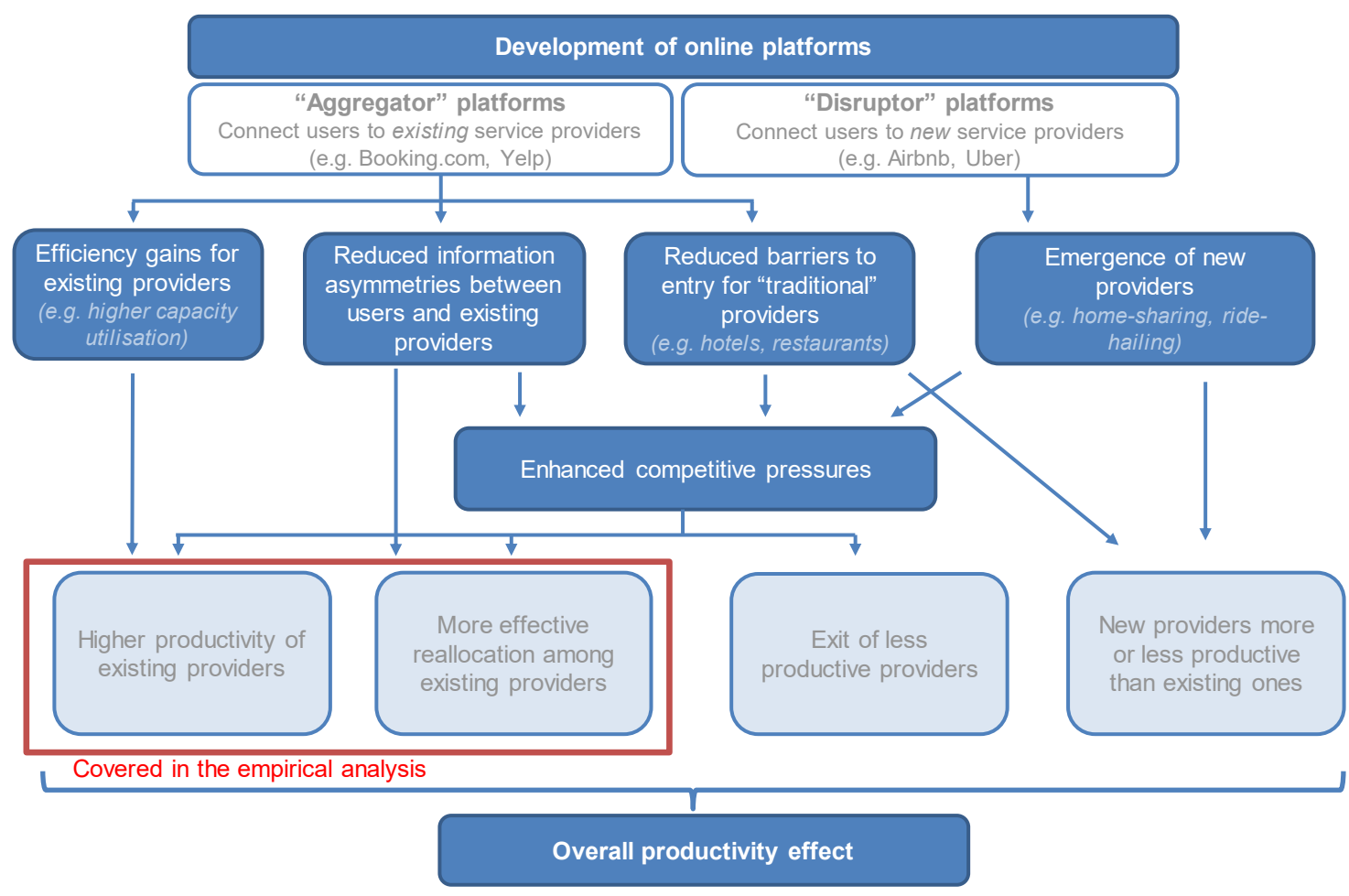

Source: OECD

13. There is very little empirical evidence on the economic effects of online platforms on service firms, and existing studies on platforms typically focus on single platforms, making them hard to generalise. To start filling this gap, this paper builds a broad indicator of platform development across countries and sectors to assess how it affects the productivity and other characteristics of service providers, and how policy-related factors can influence this link.

14. Due to data and conceptual limitations about measuring the productivity of the new providers (e.g. Uber drivers, Airbnb hosts), this paper only focuses on the productivity of incumbent service firms, considering in two different steps the productivity of the average firm (within firm component of aggregate productivity) and the reallocation effects across existing firms (between firm component). The effect on firm entry and exit are not covered because the firm-level database used in this paper (ORBIS) cannot be used for constructing a reliable measure of entry and exit, since firm coverage can vary overtime for other reasons than genuine entry into and exit from the market. In addition, the dataset does not contain (or contains only very marginally) new types of service providers, since most of them are self-employed persons (e.g. Uber drivers), private individuals or very small firms. For these reasons, the overall aggregate industry-wide or macroeconomic effects of platform development cannot be directly inferred from the empirical analysis (Figure 2), but the channels covered (within-firm and reallocation effects) still provide important insights about certain mechanisms at play and their magnitude, as well as the role of policies. 


\subsection{Potential effects of "aggregator" platforms}

15. First, "aggregator" platforms can bring efficiency gains to service providers by taking care of and rationalising certain side-activities such as managing bookings and processing payments. They can also enhance capacity utilisation (e.g. hotel occupancy rates) by making the real-time availability of services easily visible online.

16. Second, "aggregator" platforms facilitate price comparisons and provide consumers with valuable information about service quality through user ratings and reviews. This reduces information asymmetries between consumers and service providers, presumably pushing service providers to enhance service quality and value-for-money (Klein, Lambertz and Stahl, 2016 $6_{[4]}$ ). This is likely to translate into productivity gains and also a better quality of service, which will benefit consumers but not necessarily be visible in productivity figures. For example, a faster check-in system in a hotel may enable it to reduce labour inputs, increasing measured productivity. At the same time, it may also reduce waiting times for consumers, increasing their satisfaction but not measured productivity because of the difficulty to account for changes in service quality in productivity measures. ${ }^{6}$

17. The existence of ratings and reviews is also likely to reorient demand towards the better-rated service providers, allowing them to grow faster than others and also possibly resulting in the exit of the worst rated providers. ${ }^{7}$ Indeed, there is ample evidence that higher consumer ratings attract demand to providers (Resnick et al., 2006 $[5]$; Anderson and Magruder, 2012 $\left.{ }_{[6]}\right)$. Assuming that better-rated providers are more productive than average, this reallocation of demand could enhance overall productivity.

18. Finally, "aggregator" platforms can reduce barriers to entry for traditional service providers (e.g. hotels, restaurants; entry of new types of providers, such as home-sharing or ride-hailing services, is discussed in the next section). For instance, platforms can make new hotels or restaurants visible to a wider pool of potential clients, reducing advertising costs. In addition, centralised payment systems and buyer protection programmes can enhance trust in new businesses that have not yet built a reputation for reliability, for example in online retail trade. In contrast, if consumers rely heavily on platform ratings and reviews to select service providers, lacking a well-established rating can act as a barrier for new entrants. To counter this, a platform can for example make new entrants more visible for a certain time, or offer discounts on their services, until they acquire a reputation.

\footnotetext{
${ }^{6}$ In certain cases, increasing service quality may even come at the expense of measured productivity - for example, if a restaurant hires more waiters with the sole purpose of reducing consumer waiting times. However, the available evidence suggests that the trade-off between service quality and productivity is not necessarily predominant in practice (Calabrese, 2012[55]). Moreover, to the extent that improved quality is reflected in price differences across firms, the productivity measure used in this paper captures at least partly such quality improvements (Atkin, Khandelwal and Osman, 2019[58]).

${ }^{7}$ Interestingly, Klein et al. (2016 $[4]$ ) find that following an increase in market transparency on Ebay, badly-rated sellers reacted by improving their behaviour rather than exiting. However, this pattern may not necessarily apply to other activities (e.g. hotels, restaurants) where improving quality may be more difficult. For example, Luca and Luca $\left(2019_{[59]}\right)$ find that restaurants with poor ratings on Yelp are more likely to exit after minimum wage increases than better-rated restaurants.
}

Another consequence of the development of aggregator platform may be the downsizing or exit of certain firms that were also playing a role of intermediaries between consumers and services providers, such as travel agencies. 
Overall, the entry of new service providers supports employment, but their effect on aggregate productivity depends on whether the new entrants are more or less productive than the incumbents (Schwellnus et al., 2019 $\left.{ }_{[7]}\right)$.

\subsection{Potential effects of "disruptor" platforms}

19. "Disruptor" platforms, often relying on innovative business models, allow the emergence of a new type of service supply, with new services differing from existing ones but often offering sufficient similarities to compete with them (e.g. ride hailing vs. taxi, home sharing vs. hotel). This additional competition can raise the incentives for traditional service providers to increase productivity. For example, certain traditional taxi companies have adopted efficiency-enhancing features of ride-hailing platforms (e.g. online booking applications, efficient matching algorithms, use of GPS). However, this competition from new providers can also depress demand for traditional service providers, which may temporarily reduce their productivity until they adjust capacity downwards and can also reduce their profitability (especially if they were enjoying economic rents created by regulatory barriers to entry in their activity). For example, the arrival of Uber into new US cities has been found to reduce the earnings of taxis by about 10\% on average (Berger, Chen and Frey, 2018 $\left.{ }_{[8]}\right)$. Overall, it is therefore unclear ex ante in which direction the productivity of incumbent providers will be affected.

20. The impact of these new providers on aggregate productivity will also depend on their own productivity level relative to existing providers, to the extent that new providers are included in aggregate productivity estimates. However, measuring the productivity of these new providers poses important challenges, for example when they are provided by individuals (e.g. home sharing, ride sharing) both because transactions may not always be recorded and because inputs are difficult to measure. For example, measuring labour and capital inputs in home-sharing schemes to compare their productivity with hotels is not straightforward. For example, an important question is whether the capital used is a resource that was previously idle (e.g. a dwelling not occupied during the owners' holidays) or one that is fully dedicated to this service and therefore involves opportunity costs (e.g. a dwelling rented on home-sharing platforms during the whole year).

21. Leaving aside measurement challenges, it is not clear in theory if new providers are likely to be more or less productive than existing ones. On the one hand, certain innovative features benefiting new providers, such as efficient matching algorithms, can give them a productivity advantage over existing ones. For example, Uber drivers have been found to spend less idle time than taxi drivers - their average driving time per hour can be up to $50 \%$ higher than taxis (Cramer and Krueger, 2016[9]). They have also been found to offer on average lower waiting times for consumers (Rayle et al., $\left.2015_{[10]}\right)$ and to do less detours than taxis (Liu, Brynjolfsson and Dowlatabadi, 2018[11]), which both suggest a higher quality of service (but may not be visible in productivity figures). On the other hand, "disruptor" platforms also allow more non-professionals to participate in markets, who are likely to be on average less productive than specialised professionals (Schwellnus et al., $\left.2019_{[7]}\right)$.

22. These new providers often face a very different environment in terms of regulation, labour arrangements and taxation compared to existing providers. An interesting question (not explored in this paper) is the extent to which these differences in the regulatory and tax environment are driving the development of "disruptor" platforms, as compared to other differences, such as the quality of matching processes. For example, very strict regulation of incumbents (e.g. for taxis) can in certain cases lead to below-optimal service supply and 
high prices, creating more opportunities for alternative providers (e.g. Uber) to grow if they do not face the same regulatory constraints.

\subsection{Platforms' effects may depend on the intensity of competition among them}

23. Platforms define how service providers compete with each other and interact with consumers. For example, they decide which providers will have more visibility to potential consumers and how consumer ratings will be aggregated. Some platforms (e.g. Uber) also define rules about service pricing and directly match consumers with providers. All these choices by platforms are likely to influence their economic impact on service industries. For example, platforms having trustworthy rating systems can be expected to reduce information asymmetries between service providers and consumers relatively more than other platforms (Box 1). Similarly, platforms giving more visibility to new service providers will presumably contribute more to reducing barriers to entry in service sectors. For example, in the music industry, the algorithms used by Spotify to create its playlists significantly affect the probability of success of new songs and artists by making them more or less visible (Aguiar and Waldfogel, 2018 $[12]$ ).

\section{Box 1. How can platforms make consumer reviews and ratings more trustworthy?}

A trustworthy review and rating system is difficult to build and maintain, since ratings can be affected by fake reviews (Mayzlin, Dover and Chevalier, 2014 $4_{[13]}$; Luca and Zervas, 2016 ${ }_{[14]}$ ), selection biases (e.g. consumers tend to rate more often the extreme positive or negative experiences than average ones) and rating inflation (Horton and Golden, 2015 ${ }_{[15]}$; Filippas, Horton and Golden, 2018 $\left.8_{[16]}\right) .{ }^{8}$ As a result, half of respondents in a recent OECD survey of platform users across ten OECD countries reported having seen ratings and reviews that they considered to be dishonest or fake (OECD, 2017 $\left.{ }_{[17]}\right)$.

Platforms have many ways to enhance the trustworthiness of their rating and review systems (Tadelis, 2016 $6_{[18]}$; Luca, 2017 $7_{[19]}$ ). For example, platforms requiring that reviewers actually bought the service through the platform are less exposed to fake reviews (Mayzlin, Dover and Chevalier, 2014 $\left.{ }_{[13]}\right)$. Offering incentives to review (e.g. financial rewards or coupons) can reduce biases in reviewing behaviours and, in case of reciprocal reviewing, mechanisms such as "simultaneous reveal" can reduce retaliation behaviour (Li, Tadelis and Zhou, 2016 $6_{[20]}$; Fradkin, Grewal and Holtz, 2018 $\left.8_{[21]}\right)$. Clever filtering and aggregation of consumer ratings can also enhance their informative value by reducing the effect of fake reviews and cognitive biases (Dai et al., 2014 ${ }_{[22]}$; Nosko and Tadelis, 2015 ${ }_{[23]}$; Luca and Zervas, $\left.2016_{[14]}\right)$. More broadly, other policies by platforms, such as the existence of buyer protection programmes, can reduce moral hazard and enhance consumer trust (Hui et al., $\left.2016_{[24]}\right)$.

24. Since actions to enhance the trustworthiness of their rating and review system have costs, platforms can be expected to undertake them only if the associated benefits outweigh these costs. For platforms, these benefits are mainly that more trustworthy ratings and reviews enhance their perceived reliability as a platform and attract more users, or prevent

\footnotetext{
${ }^{8}$ There is a natural tendency for rating inflation on certain platforms, which may reflect that raters feel pressure to leave above average ratings to avoid harming the rated seller, which in turn pushes the average rating higher. In the long term, this can reduce the relevance of ratings if most ratings converge to the maximum possible rating.
} 
that users switch to a different platform that is perceived as more reliable. In turn, this suggests that the intensity of competition on the platform market and the importance of switching costs between platforms are likely to affect platforms' incentives to invest in rating and review quality. In a similar way, more competition between platforms may also incentivise them to tackle algorithmic collusion between service providers operating on platforms, which can be detrimental for consumers (OECD, 2017 ${ }_{[25]}$; Calvano et al., $\left.2018_{[26]}\right) .{ }^{9}$ In contrast, a very concentrated platform market can also have efficiency benefits, since a larger pool of consumers, service providers and data on transactions can enable a platform to improve its algorithms and the reliability of its ratings. The impact of the structure of the platform market is therefore an empirical question, which is explored in this paper.

25. The intensity of competition between platforms is not under direct policy control, but can be influenced by regulations affecting switching costs between platforms. These include rules on data portability (e.g. the possibility to transfer the reputation earned on a platform to another platform, or the possibility for a new platform to use anonymised data from an existing platform to train its algorithms), multi-homing (i.e. the possibility for service providers to use several platforms at the same time) and best-price clauses (i.e. clauses where platforms guarantee to their users that they get the best available price for a service, reducing consumers' incentives to test other platforms).

26. These rules can be difficult to design and involve complex trade-offs. For example, the lack of data portability may undermine platform market contestability, but "excessive" portability could pose privacy concerns and might dis-incentivise data collection in the first place. The practical aspects of data portability (e.g. lack of standard formats, fast-evolving business models of platforms) also entail important challenges. In the case of multi-homing, platforms do not typically prohibit it, but may give users important financial incentives to use almost exclusively a single platform, making it more difficult for policies to address this issue (Schwellnus et al., 2019[7] ). On best-price clauses, several European countries (e.g. Austria, France, Germany) introduced stricter rules in the hotel industry in recent years. According to a recent study on Germany, this increased the share of direct bookings with hotels and hotel chains at the expense of the main platform (Booking.com), but at the same time led more hotels to join this platform (as joining was attached to less constraints on pricing) while having no noticeable effect on platform commission rates (Hunold et al., $\left.2018_{[27]}\right)$.

27. The contestability of platform markets may also depend on merger assessment rules, in a context where the number of mergers and acquisitions (M\&A) has more than doubled since 2003 and increased relatively more in digital intensive industries (Bajgar, Criscuolo and Timmis, 2019 $\left.{ }_{[28]}\right)$. For example, large platforms may acquire innovative start-ups that have little or no revenue - hence falling below merger notification thresholds in many jurisdictions - but possess valuable user data, which in combination with the platform's own data can reinforce a platform's market position. In recent years, Austria and Germany have refined their thresholds to take into account such cases of low-revenue but high-value acquisitions.

\footnotetext{
${ }^{9}$ Stiffer competition between platforms may also incentivise them to avoid personalised pricing, a form of price discrimination that involves charging different prices to consumers according to their willingness to pay, which can erode market trust and lead to a perception of unfairness (OECD, $2018[57])$.
} 


\subsection{Other policies can influence the economic effects of platforms}

28. The economic effects of platforms are also likely to depend on the ability of service providers to adjust to rapid changes in the economic environment. For example, the emergence of platforms may lead to fast shifts in demand as consumers move towards new or better rated service providers. This can require that popular providers scale up capacity to meet the extra demand (or increase prices, but at the potential risk of losing popularity in ratings) and less popular ones scaling it back. In this more uncertain and fast-changing environment, relatively strict product and labour market regulations can be expected to hinder the ability of service providers to adjust labour and capital inputs. For example, administrative burdens and regulatory barriers may prevent certain firms from scaling up activities when demand increases. Strict employment protection may also make them reluctant to hire more employees, while also preventing firms from reducing capacity when demand declines. As a result, there can be trade-offs between flexibility for firms and protection and job quality for workers.

29. Finally, although this is beyond the scope of the empirical analysis in this paper, it is worth noting that the development of platforms itself can be influenced by the regulatory environment. As discussed above, a very strict regulation of incumbents (e.g. taxis) can stimulate the development of "disruptor" platforms enabling less-regulated providers to compete with them. In turn, some jurisdictions have tightened rules on these new providers. For example, Uber left Hungary in 2016 and Denmark in 2018 after being asked to comply with the same regulations as standard taxi services. In August 2018, New York City froze the number of licenses available to for-hire vehicles (e.g. Uber, Lyft) for one year. A number of cities (e.g. Amsterdam, Barcelona, Paris) have tightened rules on Airbnb rentals (e.g. maximum number of days per year a dwelling can be rented on the platform) and their enforcement in recent years. More broadly, the development of platforms is also likely to depend on internet accessibility and rules regarding digital trade (e.g. requirements on data privacy, regulations on e-commerce activities) and taxation.

\section{Empirical strategy to assess the economic effects of platform development}

\subsection{General approach and scope of the analysis}

30. The first step of the methodology is to build a proxy indicator of the development of online platforms across countries, industries and years, based on data from Google Trends. This indicator is matched (at a very detailed industry level) to firm-level data on the productivity of existing service firms derived from the ORBIS database. This allows to test, with two different regression models, how platform development affects (i) the productivity of the average incumbent service firm and (ii) the reallocation of resources towards the most productive of them. In each model, effects are tested separately for each of the two platform types identified above ("aggregators" and "disruptors"). Subsequently, a refinement of the empirical framework is introduced to explore how policy-related factors - such as the intensity of competition between platforms as well as product and labour market regulation - can influence these effects. Finally, the impact of platform development on mark-ups, profits, wages and employment of service providers is assessed using a similar empirical framework.

31. The empirical analysis focuses on a wide range of platforms across four industries: hotels, restaurants, taxis and retail trade. In the case of retail trade, the analysis considers five well-identified subsectors: books, shoes, cosmetics/perfumes, watches/jewellery, and 
toys. ${ }^{10}$ While platforms have developed in many other industries over recent years (e.g. personal services, air transport, entertainment, finance) these four industries (and five retail subsectors) have been selected because (i) platforms appear to have gained a central importance in these industries in many OECD countries; (ii) these industries correspond to well-identified and well-covered categories in ORBIS firm-level data, which is necessary to ensure a good matching with the platform development indicator; ${ }^{11}$ (iii) platform use and service consumption are likely to be mainly located in the same country, which would otherwise complicate the identification of effects. ${ }^{12}$ Together, the selected sectors represent roughly a quarter of non-farm business employment in OECD countries. They are generally less knowledge intensive and have a weaker productivity performance than other services (Sorbe, Gal and Millot, 2018 ${ }_{[3]}$ ). Interestingly, they face different regulatory environments - for example, taxi activities are often more strictly regulated than hotels and restaurants.

32. The analysis covers ten OECD countries: Belgium, France, Germany, Hungary, Italy, Poland, Spain, Sweden, the United Kingdom and the United States. Selected countries are those with an extensive coverage in ORBIS or large well-known platforms (e.g. United States). ${ }^{13}$ Indeed, since the industries considered are relatively narrow compared to the scope of most firm-level studies based on ORBIS, a good data coverage is essential to ensure a sufficient sample size. Results are robust to restricting the sample further, to the five selected countries with the best coverage in ORBIS over the period (Belgium, France, Italy, Spain, Sweden).

33. In each of the selected industries, a list of relevant platforms was identified based on qualitative judgement informed by a general horizon scanning exercise and various papers in the platform literature $\left(\mathrm{OECD}, 2018_{[1]}\right.$; OECD, 2019 $\left.{ }_{[2]}\right)$. Platforms are included if one of their main activities is to connect service providers to consumers, typically in a framework featuring user ratings and/or reviews (Table 1). The selection is not meant to be exhaustive, but aims to capture at least the main platforms operating in each industry and country (which represent the bulk of the variation of total platform use over time and across countries) in order to build a relevant indicator of platform overall use. The final list of more than 50 platforms included in the analysis is presented in Annex Table A.1.

34. In line with the classification outlined above, each platform is classified either as "aggregator" or "disruptor" (or "mixed" if it engages in both types of activities), based on a qualitative assessment of its business model. In the hotel industry, aggregators are mainly platforms dedicated to hotel reviewing and booking, while disruptors include home sharing activities. In the restaurant industry, all platforms considered are aggregators and their

${ }^{10}$ Retail trade is very broad and covers various activities which have not been homogenously affected by online platforms. Although the range of products sold through online platforms has significantly increased over time since the first online bookstores that appeared in the 1990s, some products (e.g. food) remain less affected by online platforms.

${ }^{11}$ For example, personal services are more difficult to match and likely to be less well covered in ORBIS since they often involve very small firms or self-employed providers. In finance and insurance, the development of platforms has not been as widespread as in the selected industries and productivity measurement poses more challenges.

${ }^{12}$ For example, providers of entertainment content on streaming platforms (e.g. Spotify, Netflix) or airline companies are often located in different countries from consumers. As discussed below, this is less frequently the case in the sectors considered in this paper.

13 Japan and Korea are not included due to the complexity of taking into account the potential use of different writing systems for Google searches. 
activities include reviewing restaurants, booking tables and in certain cases home-delivery of (generally restaurant-prepared) food. In the taxi industry, there are few aggregator platforms, whose main activity is to connect users to traditional taxis, and most platforms considered are disruptors, typically enabling ride-hailing services (the existence of for-hire vehicle services predates the development of platforms, but platforms have allowed them to increase dramatically in scale). Finally, in retail trade, most main platforms qualify both as aggregators, because they link users to existing suppliers (e.g. Amazon marketplace), and disruptors, because they engage in direct e-commerce activities that represent new entrants competing with brick-and-mortar retailers, or enable consumer-to-consumer trade of second hand products (e.g. Ebay).

Table 1. Main platforms covered in the analysis

\begin{tabular}{ccccc}
\hline & Hotels & Restaurants & Taxi & Retail subsectors \\
\cline { 2 - 5 } Aggregators & $\begin{array}{c}\text { Booking.com } \\
+13 \text { platforms }\end{array}$ & $\begin{array}{c}\text { Deliveroo } \\
+19 \text { platforms }\end{array}$ & $\begin{array}{c}\text { Easytaxi } \\
+1 \text { platform }\end{array}$ & Aliexpress \\
Disruptors & Airbnb & & Uber & Bestbuy \\
& +3 platforms & - & +6 platforms & +1 platform \\
Mixed & Homeaway & - & - & Amazon \\
& & & & +4 platforms \\
\hline
\end{tabular}

Note: The full list is presented in Annex Table A.1. The classification of platforms as aggregators, disruptors or both ("mixed") is based on a qualitative assessment of the business model of each platform and of what constitutes its primary activity over the sample period in the countries considered. Some platforms may belong to the same corporate group (e.g. Abritel, Homelidays and VRBO), which does not affect the construction of the platform use indicator, but may bias downwards the indicator of platform market concentration. Source: OECD

\subsection{Building a proxy measure of platform use based on Google Trends data}

35. As a proxy indicator for the use of a given platform in a country and year, we rely on its popularity in searches with the Google search engine. The assumption is that a platform that is increasingly used will be increasingly searched for in Google (e.g. searches for "airbnb" are assumed to indicate higher use of the Airbnb platform). For instance, potential users may search the platform name to access its website, or when looking for complementary information when using the platform (e.g. tips, troubleshooting). Admittedly, this is only a proxy measure, as Google searches do not always match actual platform use. For example, people can search information about a platform without ultimately using it. They may also enter directly the platform website or application, and such direct access may have increased in recent years with the use of dedicated apps on smartphones and tablets. Still, the variation of Google searches over time and across geographic areas is likely to be strongly correlated to platform use along these dimensions.

36. In practice, the data are retrieved from Google Trends, a public Google tool providing the volume of search for any keyword as a share of total Google searches in a given country and time period. These data are increasingly used in empirical analyses in many fields and several papers emphasize their ability to match observations from other data sources (Box 2). The platform development indicator is built for (i) all platforms, (ii) "aggregator" platforms and, (iii) "disruptor" platforms, by summing the relevant individual 
platform results for each country, industry and year. "Mixed" platforms are counted both among aggregators and disruptors. For platforms engaging in various activities (e.g. Tripadvisor provides ratings for both restaurants and hotels), the search is refined using an additional keyword (e.g. "Tripadvisor restaurant", "Tripadvisor hotels"). The same technique is used to disentangle retail subsectors (e.g. "Amazon books", "Amazon toys").

\section{Box 2. Google Trends data: main characteristics and use in empirical analysis}

Google Trends (https://trends.google.com/trends) is a facility launched by Google in May 2006. For any given keyword, it displays the number of Google searches for this keyword in a given geographic area and time period, as a share of the total number of Google web searches in that area and period. Data series start in January 2004 and virtually all countries are covered. Results take into account complex searches with multiple keywords. For example, results for "Airbnb" (without quotation marks) would include queries like "Airbnb Paris".

In practice, Google Trends presents data on a normalised scale, specific to each query, with the maximum data point always equal to 100 . The maximum number of simultaneous keywords (or combination of keywords) that can be included in a query (and therefore directly compared) is limited to five. This creates challenges to compare results across a large number of keywords and countries. To overcome this issue, the approach in this paper is to include in each query the same benchmark keyword, which is then used to normalise all other results after their extraction, making them comparable.

Over the past few years, data from Google Trends - and the former similar platform Google Insights for Search - have been increasingly used by analysts and researchers in different fields including economics but also business studies, social sciences, health care, and other sciences (Reimsbach-Kounatze, 2015 ${ }_{[29]}$ ). In economics, Google Trends data have for example been used in employment and skills studies (Askitas and Zimmermann, 2009 [30]; D'Amuri and Marcucci, 2010 [31] ), consumer sentiment analysis (Della Penna and Huang, $2009_{[32]}$ ), the analysis of trading behaviour in financial markets (Preis, Moat and Stanley, $2013_{[33]}$ ) and to forecast economic metrics such as retail good consumption and travel activities (Carrière-Swallow et al., 2013 [34]; Choi and Varian, 2012[35]; Graevenitz et al., 2016[36]; Robin, 2018[37]).

Two recent studies use Google Trends data to measure online platform development. Harris and Krueger $\left(2015_{[38]}\right)$ estimate the number of workers participating in the "online gig economy", focusing on a dozen of prominent gig economy platforms in the United States. Their estimation is broadly in line with existing estimations from other institutions using other data sources. Hunold et al. $\left(2018_{[27]}\right)$ use Google Trends data to proxy the popularity of different online travel agents among customers, and the tourism demand for hotels in particular cities, in a study assessing the effect of best-price clauses in the hotel industry. Finally, a recent assessment of Google Trends as a tool to measure tourism flows in Switzerland concludes that "search-based tourism demand predictions are, on average, highly accurate approximations of reality" (Siliverstovs and Wochner, 2018[39]).

37. Despite the limitations discussed below, the indicator suggests - in line with anecdotal evidence - that platform use has been increasing in all countries and industries considered, but with different intensity and timing (Figure 3, Figure A.1). In particular, platforms for the hotel industry took off sooner in many countries than those for restaurants and taxi services, while the intensity of platform use in retail has even declined recently in 
some countries. This decline in retail comes mainly from the book subsector and may reflect the declining the popularity of books in some countries.

Figure 3. Proxy indicator of platform use
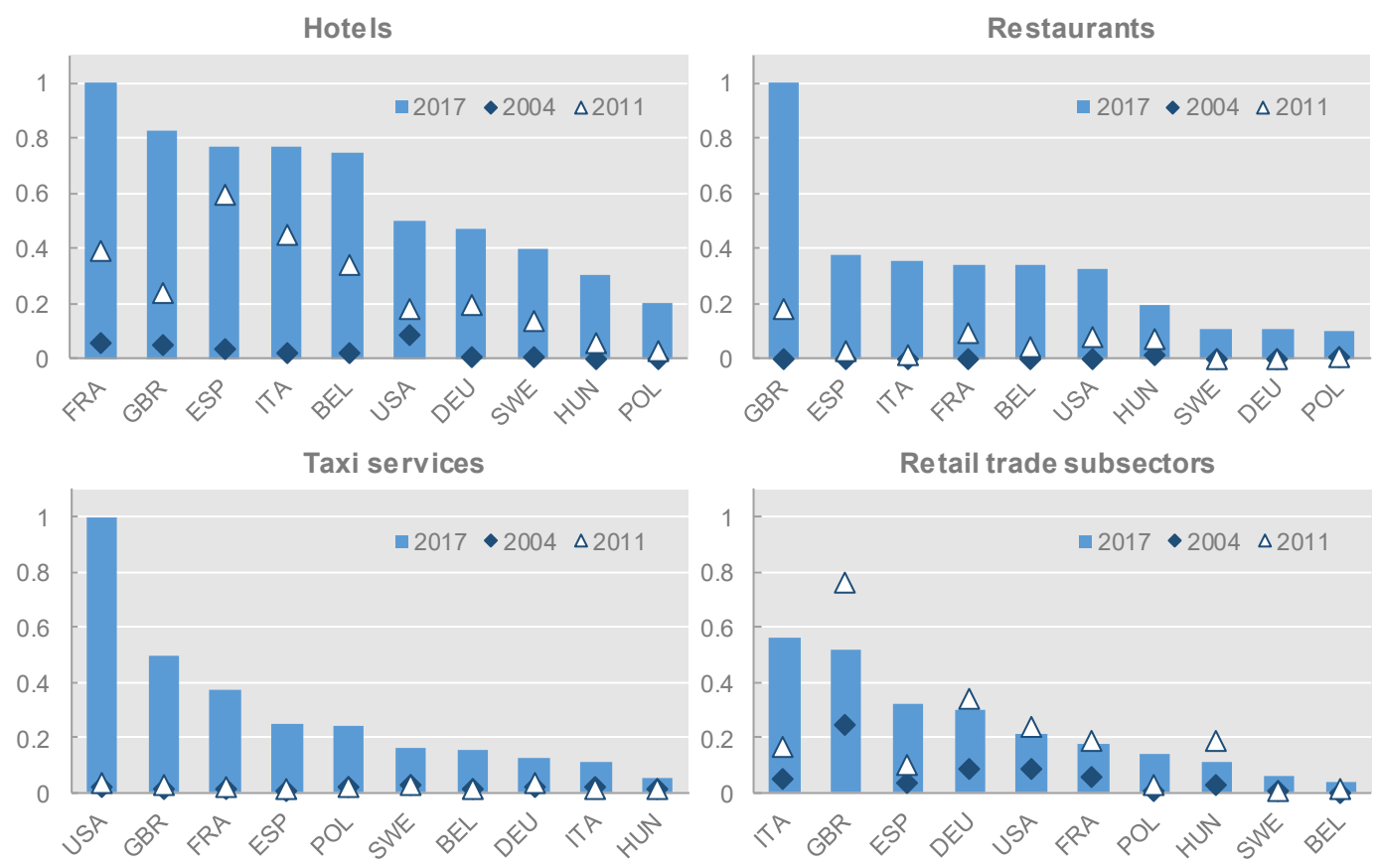

Note: The retail sector is an unweighted average of the five retail subsectors considered (books, shoes, cosmetics/perfumes, watches/jewellery, and toys). Detailed trends by country are reported in Annex Figure A.1. For each sector (and each retail subsector), values are normalised to one for the country and year with the highest platform use (usually 2017, but an earlier year in certain retail subsectors).

Source: OECD calculations, based on Google Trends data

38. While this indicator offers a unique way to capture platform development across countries, industries and years, it has the following limitations, which are partly addressed by the extensive fixed-effects structure used in the estimations:

- Although all countries are covered in Google Trends, the representativeness of the indicator can depend on the importance of Google use in the country. This issue is likely to be limited across the ten countries covered in our analysis, which all have good internet access and where Google is the main search engine. The fact that Google Trends results are always expressed as a share of total Google searches also limits potential representativeness issues.

- As discussed above, direct access to platforms through smartphone or tablet applications may bias the indicator downwards, especially in recent years. Still, the fact that the platform use indicator is increasing in almost all industries even in recent years suggests that it is not a major bias, possibly because, even when using a service through an application, users still perform internet searches including the platform name (e.g. to download or update the application and for tips and troubleshooting). This issue is addressed in the empirical analysis by the inclusion of country-year and sector-year fixed effects, which control among other things for general trends in smartphone and application use across countries and across industries. 
- Google Trends may be capturing different motives of interest, not necessarily related to the use of the platform. For example, Uber generated a large number of searches in Hungary when the platform stopped operating in the country in 2016. A screening of the sample suggests that there are very few spikes in platform popularity, suggesting that such episodes are not frequent or have little impact on the indicator. In the case of Hungary, the impact of the buzz was relatively short in time and the Google Trends series went down to nearly zero after eight months. ${ }^{14}$

- A platform can be accessed in a country to buy a service in a different country, which could bias the country dimension of the indicator. In the four sectors considered, the hotel industry is likely to be the most affected by this issue. Still, one can expect most bookings to take place within the same country. For example, despite France being a popular touristic destination among international visitors, foreigners represented only about a quarter of total hotel clients in France in 2016 (French government, 2017 $[40]$ ).

- Ambiguous meaning can also be a problem, i.e. if the name of the platform has another meaning which may generate searches unrelated to the platform. The only case where this issue occurred in the sample was the ride-hailing platform, Lyft, which means "elevator" in Swedish. Since this platform is not operating in Sweden, the series "Lyft-Sweden" was manually set to zero.

- Whereas Google Trends offers good data comparability across countries and over time, making the data comparable across sectors inevitably involves arbitrary assumptions. This is because comparing search intensities for very different platform types does not necessarily make sense due to inherent differences in the frequency of service transactions across sectors (for example, one may use and search restaurants more often than hotels). The scaling choice made in this analysis (admittedly arbitrary) is that, in each of the selected industries, the maximum value of the platform development indicator across countries and years is set to one (as presented in Figure 3). In econometric regressions, the fixed effects structure is designed to reduce the influence of this normalisation choice on the results. Reassuringly, sector-by-sector results (which are not sensitive to this normalisation assumption) are overall consistent with the results based on the pooled sample covering all four sectors.

\subsection{Firm-level data on the productivity of existing service providers}

39. The productivity of service providers is derived from the ORBIS database, a harmonised cross-country firm-level dataset provided by the electronic publishing firm Bureau Van Dijk (see Box 3 for details). The ORBIS vintage used in the analysis contains annual data up to 2016. The sample includes both unconsolidated and consolidated accounts (but either one, or the other, when firms report both) in order to maximise country coverage, as countries may apply different accounting requirements (US companies in ORBIS report their financial statement in a consolidated manner, while in most European countries the database contains mainly unconsolidated accounts).

40. Firm-level panel data on service providers based on ORBIS are matched with the platform development indicator at the country-sector-year level, based on the industry

${ }^{14}$ In this specific case, the series data was corrected manually in the affected months with linear interpolation of the values before and after the shock. 
classification code at a narrow industry level (NACE Rev.2 at the 4-digit level). After matching the two datasets, the sample is an unbalanced panel of about 160,000 firms, starting in 2004 (first year of Google Trends data) and ending in 2016 (last year of the firmlevel dataset), which represents about 700,000 firm-year observations. Table A.2 in Annex shows more details about the sample including a basic descriptive statistics on the variables used in the empirical analysis.

\section{Box 3. ORBIS firm-level data}

ORBIS is the largest cross-country firm-level database that is available and accessible for economic and financial research. However, since the information is primarily collected for use in the private sector typically with the aim of financial benchmarking, a number of steps need to be undertaken before the data can be used for economic analysis.

The steps we apply closely follow suggestions by Kalemli-Ozcan, et al. $\left(2015_{[41]}\right)$ and previous OECD experience $\left(\mathrm{Gal}, 2013_{[42]}\right)$. As discussed in Gal and Hijzen $\left(2016_{[43]}\right)$ and Andrews, Criscuolo and Gal $\left(2016_{[44]}\right)$, these data are cleaned and benchmarked using a number of common procedures such as keeping accounts that refer to entire calendar year, and dropping observations with missing information on key variables as well as outliers identified as implausible changes or ratios. Monetary variables are deflated using 2-digit industry deflators from OECD STAN and national accounts and prices are expressed in industry purchasing power parities (PPPs). Following Gal (2013 [42]), capital stock variables and firm level multi-factor productivity using several methodologies (Solow residual, Wooldridge methodology) are created. ORBIS data moreover provide information on other firm-level performance indicators such as employment, profit rates and average wages. We drop firms that report extreme growth rates in these variables, i.e. which are in the top or bottom $1 \%$ of the growth distribution within each detailed 4-digit industry. This step also serves to mitigate the risk of retaining company accounts that are affected by abrupt and large changes resulting from mergers, acquisitions or split-ups.

Labour input is measured by headcounts rather than hours worked. This can be a limitation since hours worked per employee can change over time, for example to accommodate changes in demand. Reassuringly, results are robust to including as an additional control the change in hours worked by employee at the country-industry-year level sourced from OECD STAN database.

\subsection{Testing for within-firm productivity improvements}

41. To explore the link between platform development and within-firm productivity of existing service firms, regressions of the following form are estimated:

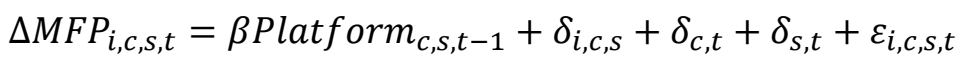

where $\Delta M F P_{i, c, s, t}$ is the log-change in multi-factor productivity of service firm $i$, operating in country $c$ and industry $s$, in year $t$. In the baseline specification, multi-factor productivity is measured as the residual from a Cobb-Douglas constant-returns-to-scale production function, with labour shares (obtained from industry-level data) fixed across countries and time but varying across industries. As robustness checks, the following alternative measures of productivity are also used: (i) labour productivity, measured as value-added 
divided by employment; (ii) an MFP estimate based on the Wooldridge $\left(2009_{[45]}\right)$ methodology (residuals from an industry-level production function estimation with nonconstrained coefficients), and (iii) a measure of MFP corrected for firm- and time-varying mark-ups (themselves estimated by the De Loecker and Warzynski $\left(2012_{[46]}\right)$ method). ${ }^{15}$

42. Platform las, $_{\text {. }}$ is the intensity of platform use in country $c$ and industry $s$, in year $t$, as measured in the previous section. The baseline specification considers the effect of the level of platform development in a given year on productivity growth in the following year. However, it is not fully clear in theory if a permanent shift in platform use (assuming it has an effect on productivity) should translate into a shift in productivity levels or growth rates. At this stage, and given how recent the development of platforms is, it seems more reasonable to assume that productivity growth rates would only be affected temporarily. This is the (conservative) choice underlying the figures illustrating the economic significance of regression results in this paper. To assess the robustness of this specification choice, three alternative specifications were also tested: (i) effect on the level of productivity of lagged platform development, (ii) effect on cumulated productivity growth over two, three or four years of lagged platform development, and (iii) effect on productivity growth of lagged platform development (as in the baseline) in a specification also including the lagged productivity level as an explanatory variable and no firm fixed effects, following Neo-Schumpeterian growth models (Aghion and Howitt, 1998 $[47]$ ). ${ }^{16}$ In all three cases, results are broadly consistent with the baseline specification (Table B.1, Table B.2). The baseline specification was preferred as it gives the most stable results across productivity measures, suggesting that it is more robust, possibly because it controls for firm-specific trends in productivity growth thanks to the presence of firm fixed effects.

43. To ensure tight identification, the model includes a very comprehensive fixed effect structure, controlling for unobserved factors along every dimension that is feasible with the data. The model includes $(i)$ country-year fixed effects $\left(\delta_{c, t}\right)$ to control for time-varying country-specific trends and shocks (e.g. macroeconomic factors or country specific trends in internet use or smartphone penetration); (ii) industry-year fixed effects $\left(\delta_{s, t}\right)$ to control for time-varying global industry factors (e.g. general technological and market structure changes); and (iii) firm fixed effects $\left(\delta_{i, c, s}\right)$ to capture firm-specific characteristics that do not change over time (country, industry, but also location and some aspects of specialisation, management and organisation). ${ }^{17,18}$ This choice of fixed effect structure implies that the identification comes from cross-country differences in within-industry patterns of platform use over time and that the data is purged from time-varying aggregate shocks. Standard errors are adjusted by two-way clustering, at the country-industry-year level (to match the level of variation in the platform use indicator) and at the firm level (to

\footnotetext{
${ }^{15}$ The mark-up corrected MFP measure assumes intermediate inputs as the flexible production factor and uses a gross output based production function.

16 The simultaneous the inclusion of lagged productivity level and firm fixed-effects would potentially bias the estimation (Nickell bias) especially in presence of firm-fixed effects (Nickell, $\left.1981_{[56]}\right)$. Instead, controls for firm size and age are included. Given that industry-time fixed effects are included, the lagged productivity level variable is equivalent to the distance to the distance to the global industry-wide productivity frontier.

${ }^{17}$ Since firms do not change across industries in the dataset, firm fixed effects are fully nested into country-industry cells, hence there is no need to include country-industry fixed effects separately.

${ }^{18}$ Including firm fixed effects reduces the need to include further control variables such as firm size and age.
} 
allow for serially correlated error terms at the firm level) in line with current practice (Cameron, Gelbach and Miller, 2011 [48]; Feyrer, Mansur and Sacerdote, 2017 ${ }_{[49]}$ ).

44. The main parameter of interest is $\beta$, which is expected to be positive if stronger platform use, conditional on the rich set of fixed effects included, is associated with faster within-firm productivity growth of service providers. The effect of all platforms (regardless of their type) and of the two platform types described above ("aggregators" and "disruptors") are tested separately. In practice, certain platforms are classified as belonging to both groups due to their diverse activities (e.g. Amazon). This implies that there is some overlap between the groups, which is why they are included in separate regressions. Sectorspecific effects are also explored by re-estimating Equation 1 separately for each sector. In these cases, country-year fixed effects would absorb the platform use indicator, hence simple year fixed effects are used instead $\left(\delta_{\mathrm{t}}\right)$.

45. Endogeneity issues are likely to be limited, thanks to the very comprehensive fixed effect structure and the fact that the platform development variable is lagged by one year. Still, two types of endogeneity issues may conceivably exist. First, it is possible that a country-sector-year specific shock (e.g. more demand for accommodation services in Spain in a given year) supports both platform development and capacity utilisation in this industry, which would lead to higher productivity growth. However, such a shock would have to be very specific as fixed effects control for all country-wide and or sector-wide shocks. It would also have to have some persistence, since it would need to affect platform development in one year and productivity growth in the following year, which seems rather unlikely. To test robustness to this potential issue, an additional control variable is built from Google Trends, using the name of each sector as a keyword (e.g. "hotel", "restaurant") to proxy for overall changes in demand in each country, industry and year. Results are robust to including this additional control, either contemporary or lagged by one year (Annex Table B.3).

46. Second, "disruptor" platforms could appear at a faster pace when traditional service providers underperform (e.g. due to overly strict regulations), hence leading to reverse causality and a negative correlation between productivity growth and platform use (making the identification of positive productivity effects more difficult). However, the inclusion of firm fixed effects, which capture the long-term productivity performance of firms in the sector, largely mitigates this risk.

\subsection{Testing for improvements in allocative efficiency}

47. To explore whether platform use leads to improvements in allocative efficiency, the following specification is estimated, building on standards models of dynamic allocative efficiency (Foster, Grim and Haltiwanger, 2016 [50]; Decker et al., 2017 [51]). The idea is to test whether employment growth is higher in firms that are more productive (which is usually the case) and if this effect is stronger in sectors where platforms are used intensively:

$$
\begin{aligned}
\Delta L_{i, c, s, t}=\beta_{1} \widetilde{M F P}_{i, c, s, t-1}+\beta_{2} \widetilde{M F P}_{i, c, s, t-1} \times \text { Platform }_{c, s, t-1} \\
+\sum_{t} \delta_{t} \widetilde{M F P}_{i, c, s, t-1}+\sum_{s} \delta_{s} \widetilde{M F P}_{i, c, s, t-1}+\beta_{3} X_{i, c, s, t} \\
+\delta_{c, s, t}+\varepsilon_{i, c, s, t}
\end{aligned}
$$

where $\Delta L_{i, c, s, t}$ is the log-change in employment in service firm $i$ (country $c$ and industry $s$ ), in year $t$. The coefficient $\beta_{1}$ is expected to be positive in presence of positive reallocation 
effects towards more productive firms. The main coefficient of interest is $\beta_{2}$, which is expected to be positive if platform development reinforces this positive reallocation. $\widehat{M F P}_{i, c, s, t-1}$ denotes lagged multifactor productivity, demeaned by country-sector-year cells to capture the within-sector position of firms in the productivity distribution. The implication is that the model focuses on within-industry reallocation.

48. As in the previous model, very comprehensive fixed effects are included, in the form a triple interacted fixed effect $\delta_{c, s, t}$ which controls for all country-industry specific time-varying factors (e.g. all macro-sectoral developments that can affect employment growth in a given industry, country and year). ${ }^{19}$ Year dummies interacted with lagged MFP are also included to allow the strength of reallocation to vary overtime - in line with the finding that allocative efficiency has been significantly worsening over the past decade (Decker et al., 2016 $[52]$; Adalet McGowan, Andrews and Millot, 2017 $[53]) .{ }^{20}$ Sector dummies are also interacted with lagged MFP to allow the intensity of reallocation to vary across industries. ${ }^{21}$ Finally, a vector of control variables $\left(X_{i, c, s, t}\right)$ including firm size and age is also included.

49. Similarly to the previous model, the effect of all platforms and of the two identified platform types (aggregators and disruptors) is tested separately. In addition to the crosssector regressions, sector-by-sector estimations are carried out, in which the country-sectoryear fixed effects are replaced by country-year fixed effects $\left(\delta_{c, t}\right)$.

\subsection{Assessing the effect of policies on platform-productivity links}

50. Two policy-related questions are considered. First, does the intensity of competition between platforms influence the productivity of service providers? Second, is the effect of platforms affected by product and labour market regulations that may alter the ability of service providers to adjust in front of economic shocks such as platform development? For both questions, the experiment consists of modifying Equation 1 to introduce the interaction of a policy-related variable with platform development (Equation 3). Both the platform and the policy variable are demeaned in the interaction term to ensure that the estimated coefficients correspond to average effects. ${ }^{22}$

$$
\begin{aligned}
\Delta \text { MFP }_{i, c, s, t}=\beta_{1} & \text { Platform }_{c, s, t-1} \\
& +\beta_{2}\left({\widetilde{\text { Pollc }_{c, s, t-1}}} \times \text { Platform }_{c, s, t-1}\right)+\delta_{c, t} \\
& +\delta_{s, t}+\delta_{i, c, s}+\varepsilon_{i, c, s, t}
\end{aligned}
$$

51. The intensity of competition between platforms is difficult to define and measure, since both competition on the market and for the market (i.e. contestability of the market) can be relevant. The market share of the largest platform is used as a proxy for competition

\footnotetext{
${ }^{19}$ This implies that the effect of platform development (which is measured at the country-industryyear level) cannot be estimated directly, but only through its interaction with lagged MFP.

${ }^{20}$ We do not include firm fixed effects, as in Equation 1, because they would absorb all timeinvariant variation across firms, including average productivity levels, while that is a key source of variation for the identification of a reallocation model.

${ }^{21}$ This also addresses potential issues of comparability across sectors in the Google Trends data.

${ }^{22}$ To reduce the potential effect of the relative lack of comparability of platform intensity use across sectors (as discussed in section 3.2), the platform variable is demeaned by sector in the interaction term.
} 
on the market. A proxy measure of it is derived from the Google Trends data, dividing the popularity of the largest platform in a given country, industry and year, by the total popularity of all platforms in that country, industry and year. This measure of concentration tends to be higher than average in the taxi industry and lower than average in hotels (Figure 4). The persistence at the top of the largest platform in an industry is used as a proxy for competition for the market. The variable used to capture this persistence is a dummy equal to one when the largest platform in a country and industry was already the largest in the previous year, or alternatively in the two previous years.

Figure 4. The contestability of platform markets varies across industries

Panel A: Market share of the largest platform (average across sample countries)

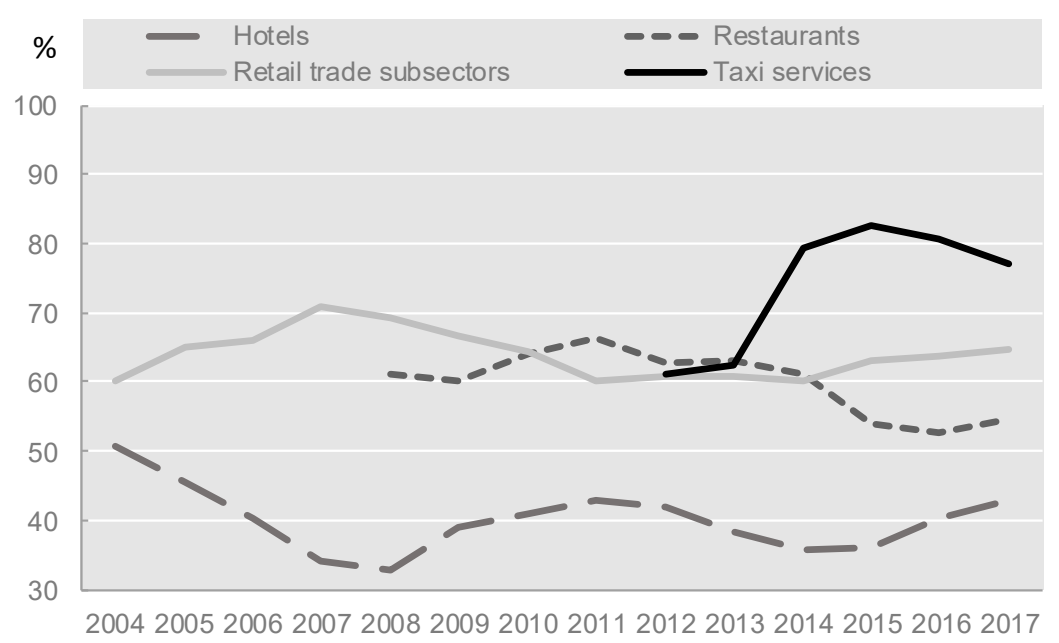

Panel B: Share of countries where the largest platform in an industry was already the largest in the two previous years

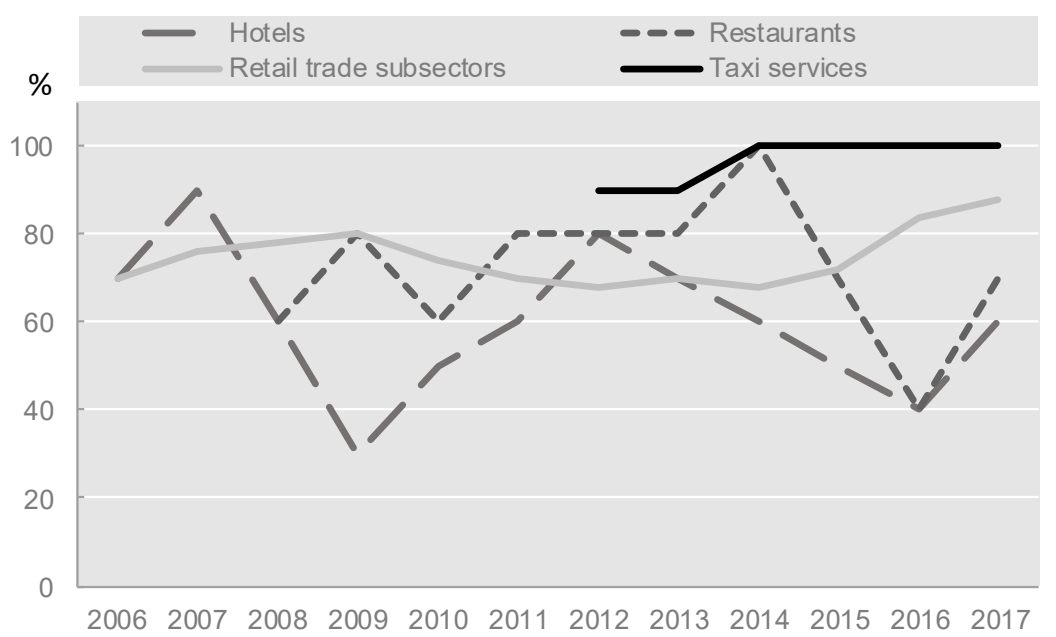

Note: Unweighted average across sample countries. The retail sector is an unweighted average of the five retail subsectors considered (books, shoes, cosmetics/perfumes, watches/jewellery, and toys). Industry-years where platform development is very limited (below $4 \%$ of the maximum platform development observed in the sample) are omitted. The "market share" of a platform is defined as the share of Google searches in each country, industry and year.

Source: OECD calculations based on Google Trends. 
52. Equation 3 is also estimated with other policy variables to assess if regulatory policies in labour and product markets influence the productivity effects of platform development (e.g. by hindering the ability of service providers to adjust to rapid changes in the economic environment induced by platforms). Two variables are tested: (i) the OECD indicator of employment protection legislation (EPL) on temporary contracts, assuming that these contracts are frequently used in the industries considered and that temporary workers are likely to represent an important part of adjustment to economic changes, and (ii) the "barriers to entrepreneurship" component of the OECD product market regulation (PMR) indictor, which captures factors such as the complexity of regulatory procedures and administrative burdens on firms.

\subsection{Effect of platforms on other characteristics of service providers}

53. Equation 1 is re-estimated, replacing the dependent variable with (i) mark-ups, which are estimated by assuming intermediate inputs to be the variable input in a gross output based production function (De Loecker and Warzynski, 2012[46]); (ii) profit rates, which are measured as earnings before interest, depreciation and amortisation (EBITDA) as a fraction of gross output (measured by operating revenues), (iii) real wages, measured by labour costs per employee deflated by the industry-level output deflator and (iv) employment.

54. The mechanisms through which mark-ups and profits of existing service providers can be affected by platform use are manifold. Assuming monopolistic competition between service providers, they can lead to an ambiguous sign a priori: on the one hand, (i) increased competitive pressures induced by reviews and ratings as well as the emergence of new providers can reduce mark-ups (especially if these mark-ups reflected that incumbents were sheltered from competition by protective regulations); in addition, certain providers can face lower demand due to competition from new providers (e.g. hotels following the development of Airbnb) implying lower mark-ups until they adjust capacity downwards; (ii) service providers' mark-ups may also be reduced by aggregator platforms charging commissions to use their service, ${ }^{23}$ on the other hand, (iii) productivity gains resulting from platform development (as estimated in Equation 1) can translate into higher mark-ups; (iv) reduced information asymmetries and higher service quality can lead to overall higher demand for services, which can also push mark-ups higher. ${ }^{24}$

55. Similarly, the impact on labour market outcomes - wages and employment - in the services where platforms operate can be either positive (due to higher demand) or negative (due to tougher competition), depending on which channels dominate empirically (Schwellnus et al., 2019 $[7]$ ).

\footnotetext{
${ }^{23}$ For example, Booking.com takes a commission ranging between $10 \%$ and $25 \%$ of the price of hotel bookings, depending on property type or location (source: https://partnerhelp.booking.com/hc/en-us/articles/212708929-How-much-commission-do-I-pay-).
}

${ }^{24}$ Since quality and market power cannot be disentangled when estimating mark-ups, an increase in quality induced by platform development may also lead to an apparent increase in mark-ups. 


\section{Results}

\subsection{Platforms increase the average productivity of service providers}

56. The baseline results suggest that the development of online platforms in an industry stimulates the productivity of the average incumbent firm in this industry (Table 2). ${ }^{25}$ The effect is economically significant. For example, the increase in platform use observed over 2011-17 in the industries considered (hotels, restaurants, taxis and retail) among the sample countries with above-average (below-average) platform development is found to have increased productivity of the average incumbent in these industries by about 2.5 percent (1 percent). ${ }^{26}$ These effects are substantially higher than over the previous period (2004-10), during which platform development was less widespread across sectors (Figure 5).

Table 2. Effect of online platforms on the productivity of existing service providers, baseline results

\begin{tabular}{|c|c|c|c|}
\hline & (1) & $(2)$ & (3) \\
\hline & \multicolumn{3}{|c|}{ Dependent variable: $\triangle M F P i, t$} \\
\hline \multirow[t]{2}{*}{ All platforms $\mathrm{c}_{\mathrm{c}, \mathrm{s}, \mathrm{t}-1}$} & $0.08193^{* * *}$ & & \\
\hline & $(0.032)$ & & \\
\hline \multirow{2}{*}{ Aggregators $_{\mathrm{c}, \mathrm{s}, \mathrm{t}-1}$} & & $0.10434^{* * *}$ & \\
\hline & & $(0.032)$ & \\
\hline \multirow[t]{2}{*}{ Disruptors $_{c, s, t-1}$} & & & 0.01966 \\
\hline & & & $(0.041)$ \\
\hline Firm fix ed effects & YES & YES & YES \\
\hline Country*Year fix ed effects & YES & YES & YES \\
\hline Industry *Year fix ed effects & YES & YES & YES \\
\hline Observations & 701,304 & 701,304 & 701,304 \\
\hline R2 & 0.171 & 0.171 & 0.171 \\
\hline
\end{tabular}

Note: The equation estimated corresponds to Equation 1. $\triangle \mathrm{MFP}$ is the 1-year multifactor productivity growth of firm $i$ in year $t$, based on Solow residual estimations. The three platform variables correspond to the popularity of (i) all platforms, (ii) "aggregator" platforms (e.g. Booking.com, TheFork), (iii) "disruptor" platforms (e.g. Airbnb, Uber). Industry refers to 4-digit level NACE sectors, namely hotels (5510), restaurants (5610), taxi (4932), retail trade of books (4761), of toys (4765), of shoes (4772), of perfume and cosmetics (4775) and of watches and jewellery (4777). The sample covers BEL, DEU, ESP, FRA, GBR, HUN, ITA, POL, SWE, USA over 2004-2016. Country*Industry fixed effects are also captured by the firm fixed effects as these variables are firm-specific and time-invariant in the Orbis dataset. Robust standard errors are clustered by firm and by country-industry-year. $* * *$ denotes statistical significance at the $1 \%$ level, ${ }^{* *}$ significance at the $5 \%$ level, * significance at the $10 \%$ level.

Source: OECD calculations based on ORBIS and Google Trends.

25 The relatively low R-squared is typical of firm-level analyses with high observation numbers.

26 This estimate is based on the (conservative) assumption that the impact of platform development on productivity growth is not persistent in time, and therefore corresponds to a one-off shift in productivity levels. This is consistent with the results of alternative specifications presented in Annex Table B.1 and Table B.2. Indeed, the coefficient of interest remains close to the baseline in specifications replacing annual productivity growth as the dependent variable by productivity growth cumulated over two, three and four years, and also in the level-on-level specification. Finally, the specification based on a Neo-Schumpeterian model suggests effects of similar magnitude over the medium term. Longer-term effects are anyway difficult to anticipate given that platform development is a recent phenomenon and that platform business models can evolve rapidly. 


\section{Figure 5. Impact of platform development on the productivity of service providers}

Total effect of platform development on multi-factor productivity of the average service firm, unweighted average of the effect across selected industries (hotels, restaurants, taxis and retail)

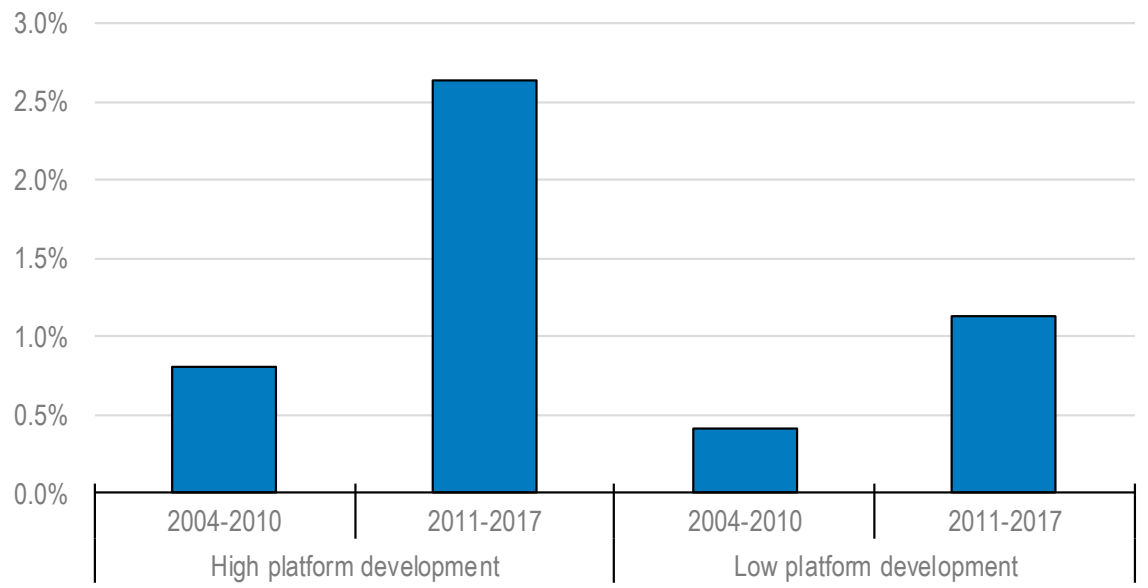

Note: "High platform development" is the average of the five countries where the platform development indicator is above median on average over the 2004-17 period (France, Italy, Spain, United Kingdom, United States), while "Low platform development" is the average of the five other countries in the sample (Belgium, Germany, Hungary, Poland, Sweden). The estimated impact is calculated by multiplying the coefficient estimated in Table 2 for all platforms (column 1) by the change in the platform indicator in each country (unweighted average of the four considered sectors, retail being itself the unweighted average of the five subsectors composing it) over 2004-10 and 2011-17. These averages do not take into account that effects of platforms can vary depending on structural and policy factors, as shown below. All identified factors influencing country-specific impacts are presented in Table 8.

Source: OECD calculations based on ORBIS and Google Trends.

57. These productivity gains come from "aggregator" platforms, whose main focus is to connect consumers to existing service providers. In contrast, "disruptor" platforms, which enable new types of service providers to emerge, have no significant effect on the productivity of existing service providers. This may be because of two opposite effects: these new providers increase competitive pressures on existing service providers giving them incentives to increase their productivity, but their also absorb part of the overall demand for services, which may reduce capacity utilisation of existing providers at least in the short term (until they adjust capacity downwards).

58. Results by sector give a picture consistent with these cross-sector results (Table 3). "Aggregator" platforms have a positive and significant effect on firms' productivity in the hotel, restaurant and retail sectors. Results for "disruptor" platforms are mixed (positive effect in retail and negative in hotels) reflecting the opposing effects mentioned above. Only in the taxi industry are no results significant, possibly reflecting a partial geographic mismatch between the coverage of traditional taxi firms and alternative providers (e.g. Uber) which typically focus only on the largest cities. Another potential issue in the taxi industry is that the potential for productivity gains is inherently relatively limited, since productivity gains can mainly come from reducing drivers' idle time.

59. The results for the pooled sample including all sectors presented in Table 2 are robust to using alternative specifications based on MFP levels or long differences (Table B.1 and Table B.2). Results are also robust to including an additional control variable capturing country-industry-year specific changes in demand, based on Google Trends queries using generic keywords such as "hotel" or "restaurant" (Table B.3). This confirms that results are driven by platform development, rather than specific demand 
shocks affecting simultaneously platform use and service firms' productivity. Finally, results are robust to using alternative productivity measures, including a measure of productivity corrected for mark-ups (Table B.4) and to restricting the sample to the five countries with the best coverage in ORBIS (Table B.5). ${ }^{27}$

Table 3. Effect of online platforms on the productivity of existing service providers, sector-specific results

\begin{tabular}{lccc}
\hline & All platforms & Aggregators & Disruptors \\
\hline Hotels & 0.080 & $0.161^{* *}$ & $-0.359^{* *}$ \\
Restaurants & $0.262^{* *}$ & $0.262^{* *}$ & n.a. ${ }^{1}$ \\
Taxi & -0.314 & n.a. ${ }^{1}$ & -0.336 \\
Retail subsectors & $0.082^{* *}$ & $0.092^{* *}$ & $0.083^{* *}$ \\
\hline
\end{tabular}

Note: The table presents the results of regressions of within-firm productivity growth on platform use (Table 2) run separately on each sector. Hotels refer to the NACE classification code 5510, restaurants 5610, taxi 4932, and retail subsectors comprise books (4761), toys (4765), shoes (4772), perfume and cosmetics (4775) and watches and jewellery (4777). Only the sign of results with at least $10 \%$ significance level are reported. For example, in the hotel sector, the regression with all platforms gives insignificant results, the regression with "aggregators" gives positive and significant results and the regression with "disruptor" platforms gives negative and significant results. The detailed regression results are presented in Table B.6.

${ }^{1}$ All platforms in the restaurants sector are Aggregators, while Aggregators are absent in most countries in the taxi sector.

Source: OECD calculations based on ORBIS and Google Trends.

\subsection{Platform use and labour reallocation among existing service providers}

60. The baseline results for the reallocation model (estimation of Equation 2) suggest that online platforms support the reallocation of labour to more productive service firms (Table 4). Indeed, the baseline effect of lagged MFP (first line) is positive, confirming that productivity-enhancing reallocation is taking place in the considered industries and countries, and the interaction with platform development $\left(2^{\text {nd }}\right.$ to $4^{\text {th }}$ line $)$ is also positive (although not statistically significant for disruptor platforms), suggesting that the intensity of reallocation increases with platform development. The effect is economically significant since in the countries with relatively strong platform uptake, it has been sufficient to counteract the broader trend toward declining reallocation intensity documented in past studies (Figure 6). ${ }^{28}$

${ }^{27}$ Additional results available upon request suggest that effects are relatively homogeneous across different types of firms. Indeed, the estimated elasticities are broadly stable across groups of firms defined by their size, age, or productivity levels.

${ }^{28}$ See for example Foster et al. (2016[50]), Decker et al. (2017[51]), Adalet McGowan et al. (2017 $\left.7_{[53]}\right)$. 
Table 4. Effect of online platforms on allocative efficiency, baseline results

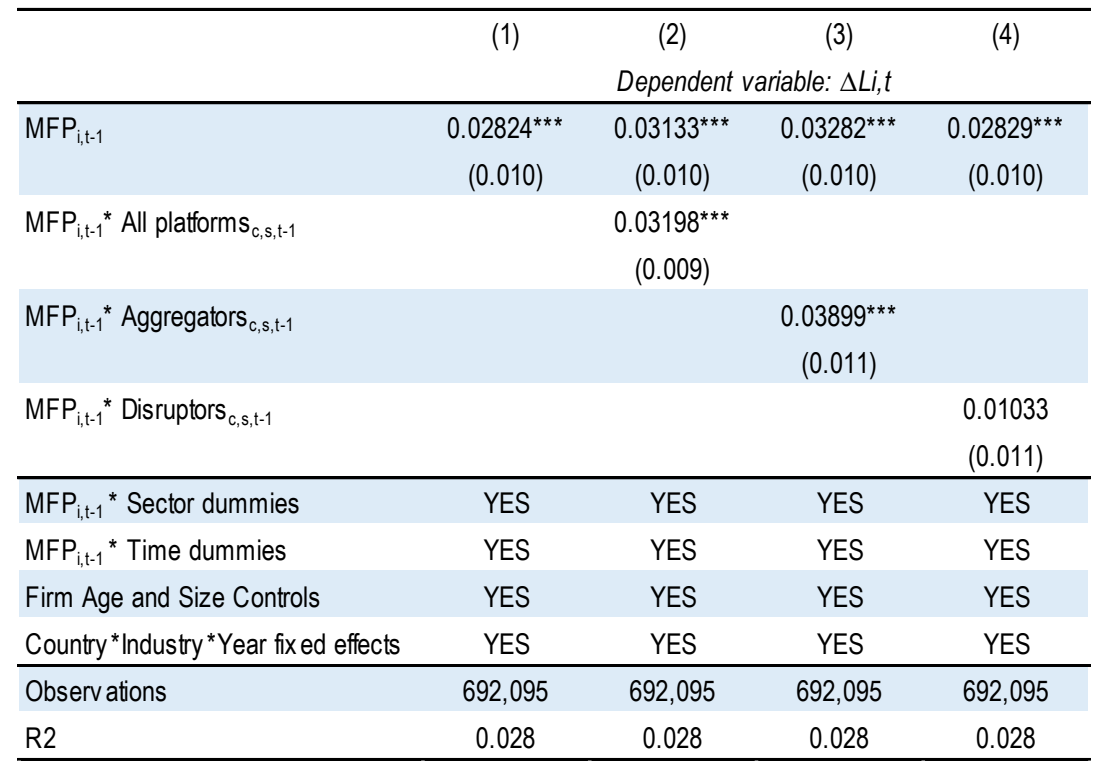

Note: The equation estimated corresponds to Equation 2. $\Delta \mathrm{L}$ denotes the 1-year employment growth at the firmlevel. MFP denotes firm's multifactor productivity, based on Solow residual estimations, defined as the deviation from country-industry-year mean. The 3 platform variables correspond to the popularity of (i) all platforms, (ii) "aggregator" platforms (e.g. Booking.com, TheFork), (iii) "disruptors" platforms (e.g. Airbnb, Uber). Industry refers to 4-digit level NACE sectors, namely hotels (5510), restaurants (5610), taxi (4932), retail trade of books (4761), of toys (4765), of shoes (4772), of perfume and cosmetics (4775) and of watches and jewellery (4777). The sample covers BEL, DEU, ESP, FRA, GBR, HUN, ITA, POL, SWE, USA over 2004-2016. Robust standard errors are clustered by firm and by country-industry-year. *** denotes statistical significance at the $1 \%$ level, ** significance at the $5 \%$ level, * significance at the $10 \%$ level. Source: OECD calculations based on ORBIS and Google Trends.

Figure 6. Intensity of labour reallocation to the more productive firms

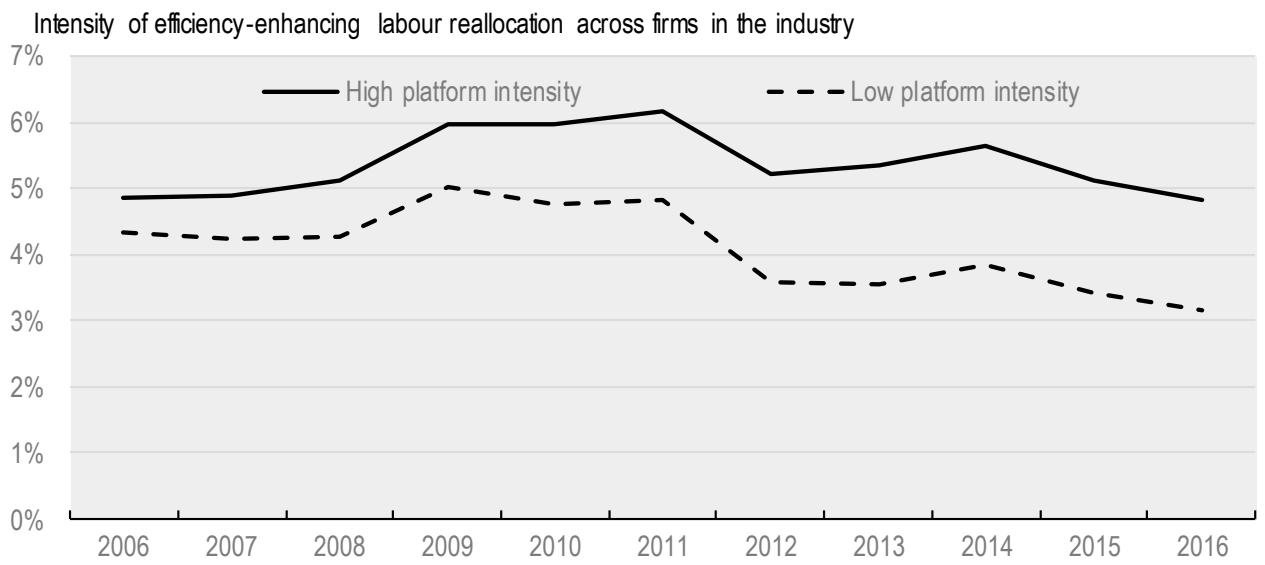

Note: The intensity of labour reallocation corresponds to the coefficient $\beta_{1}$ in Equation 2, i.e. the effect of lagged productivity level on employment growth. For example, a 5\% coefficient implies that a firm with $10 \%$ higher MFP will enjoy $0.5 \%$ higher labour productivity growth. The coefficient is estimated for each year by interacting lagged MFP with year dummies. The two lines correspond to high and low platform intensity (i.e. sectors at the $75^{\text {th }}$ and $25^{\text {th }}$ percentile of the distribution of platform intensity across countries and industries). Source: OECD calculations based on ORBIS and Google Trends. 
61. Sector-by-sector results are consistent with the cross-sector picture (Table 5). In most sectors, platforms have a positive effect on reallocation thanks to "aggregator" platforms, while "disruptor" platforms have no significant effect. Similarly to the withinfirm model, results are robust to using alternative productivity measures (Table B.7), and to restricting the sample to the five countries with the best coverage in ORBIS (Table B.8).

Table 5. Effect of online platforms on allocative efficiency, sector-specific results

\begin{tabular}{lccc}
\hline & All platforms & Aggregators & Disruptors \\
\hline Hotels & $0.057^{* * *}$ & $0.068^{* * *}$ & 0.109 \\
Restaurants & $0.130^{* * *}$ & $0.130^{* * *}$ & n.a. ${ }^{1}$ \\
Taxi & -0.157 & n.a. & -0.196 \\
Retail subsectors & -0.006 & -0.007 & -0.006 \\
\hline
\end{tabular}

Note: The table presents the results of regressions of within-firm employment growth on lagged multifactor productivity level (Solow residual) interacted with platform use (Table 4), run separately on each sector. Hotels refer to the NACE classification code 5510, restaurants 5610, taxi 4932, and retail subsectors comprise books (4761), toys (4765), shoes (4772), perfume and cosmetics (4775) and watches and jewellery (4777). Only the sign of results with at least $10 \%$ significance level are reported. For example, in the hotel sector, the regressions with all platforms and "aggregator" gives positive and significant results and the regression with "disruptor" platforms no significant results. The detailed regression results are presented in Table B.9.

${ }_{1}^{1}$ All platforms in the restaurants sector are Aggregators, while Aggregators are absent in most countries in the taxi sector.

Source: OECD calculations based on ORBIS and Google Trends.

\subsection{Effect of competition between platforms}

62. The structure of the platform market is found to have an influence on the productivity of service providers, with rivalry among platforms enhancing efficiency improvements in services. Regression results suggest that a highly concentrated platform market (market share of the largest platform above the median in the sample, which is 64\%) brings significantly less productivity benefits than a less concentrated one (Table 6, column 1). This suggests that the efficiency loss from insufficient competition between platforms (which can lead for example to lower incentives to invest in trustworthy ratings and reviews) outweighs the efficiency gain from having a large platform dominating the market (with richer data and therefore potentially able to offer better services).

63. Results are robust to (i) using a different threshold to identify high market concentration (the $75^{\text {th }}$ percentile of the sample, which corresponds to a $85 \%$ market share, instead of the median), and (ii) using a continuous variable with the market share of the largest platform (Table B.10). Results are also robust to considering all platforms rather than only "aggregator" platforms. 
Table 6. Effect of online platforms on the productivity of existing service providers, effect of competition on the platform market

\begin{tabular}{|c|c|c|}
\hline & (1) & (2) \\
\hline & \multicolumn{2}{|c|}{ Dependent variable: $\triangle M F P i, t$} \\
\hline \multirow[t]{2}{*}{ Aggregators $_{c, s, t-1}$} & $0.13642^{* * *}$ & $0.11958^{* * *}$ \\
\hline & $(0.035)$ & $(0.035)$ \\
\hline \multirow[t]{2}{*}{ Aggregators ${ }^{*}$ Concentrated $d_{c, s, t-1-1}$} & $-0.08236^{* * *}$ & \\
\hline & $(0.030)$ & \\
\hline \multirow[t]{2}{*}{ Aggregators ${ }^{*}$ Concentrated ${ }^{*}$ Persistent $t_{c, s, t-1{ }^{*}}$} & & $-0.08842^{* * *}$ \\
\hline & & $(0.031)$ \\
\hline \multirow[t]{2}{*}{ Aggregators ${ }^{*}$ Concentrated ${ }^{*}$ NonPersistent $t_{c, s, t-11^{*}}$} & & -0.02390 \\
\hline & & $(0.065)$ \\
\hline Firm fix ed effects & YES & YES \\
\hline Country ${ }^{*}$ Year fix ed effects & YES & YES \\
\hline Industry *Year fix ed effects & YES & YES \\
\hline Observations & 701,304 & 610,287 \\
\hline R2 & 0.171 & 0.181 \\
\hline
\end{tabular}

Note: The equation estimated in the first column corresponds to Equation 3, where the platform variable (Aggregators) corresponds to the popularity of "aggregator" platforms in each country-industry-year, and the policy variable to a dummy Concentrated taking the value one when the largest platform in a country-industryyear has a market share above the median in the sample. In the second column, the concentration variable is interacted with a persistence dummy variable taking the value of one when the largest platform in a country and industry was already the largest in the two previous years. $\triangle \mathrm{MFP}$ is the 1-year multifactor productivity growth of firm $i$ in year $t$, based on Solow residual estimations. Industry refers to 4-digit level NACE sectors, namely hotels (5510), restaurants (5610), taxi (4932), retail trade of books (4761), of toys (4765), of shoes (4772), of perfume and cosmetics (4775) and of watches and jewellery (4777). The sample covers BEL, DEU, ESP, FRA, GBR, HUN, ITA, POL, SWE, USA over 2004-2016. The regressions also include the dummy variable Concentrated ${ }_{c, s, t-1}$ (in column 1) and the double interactions Concentrated ${ }^{*}$ Persistent $_{c, s, t-1}$ and

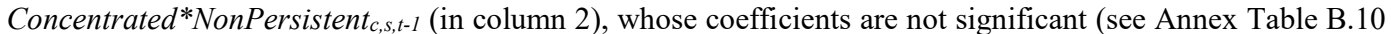
for the full results, as well as results with alternative concentration variables). Robust standard errors are clustered by firm and by country-industry-year. $* * *$ denotes statistical significance at the $1 \%$ level, $* *$ significance at the $5 \%$ level, $*$ significance at the $10 \%$ level.

Source: OECD calculations based on Orbis and Google Trends.

64. Interestingly, a concentrated platform market is only detrimental when the domination of the largest platform is persistent in time (as measured by a dummy variable equal to one when the largest platform in a country and industry was already the largest in the previous year, or alternatively the two previous years). Results (Table 6, column 2; Figure 7) suggest that productivity gains are not significantly different from the baseline (i.e. a weakly concentrated platform market) when the domination of the largest platform is not persistent over time. This may reflect that in this case, market contestability has positive effects on platform behaviour (e.g. good incentives to invest in trustworthy ratings and reviews). 


\section{Figure 7. More competition between platforms leads to higher productivity benefits}

Effect of platform development on average service firm productivity in the selected industries and countries, depending on the structure of the platform market

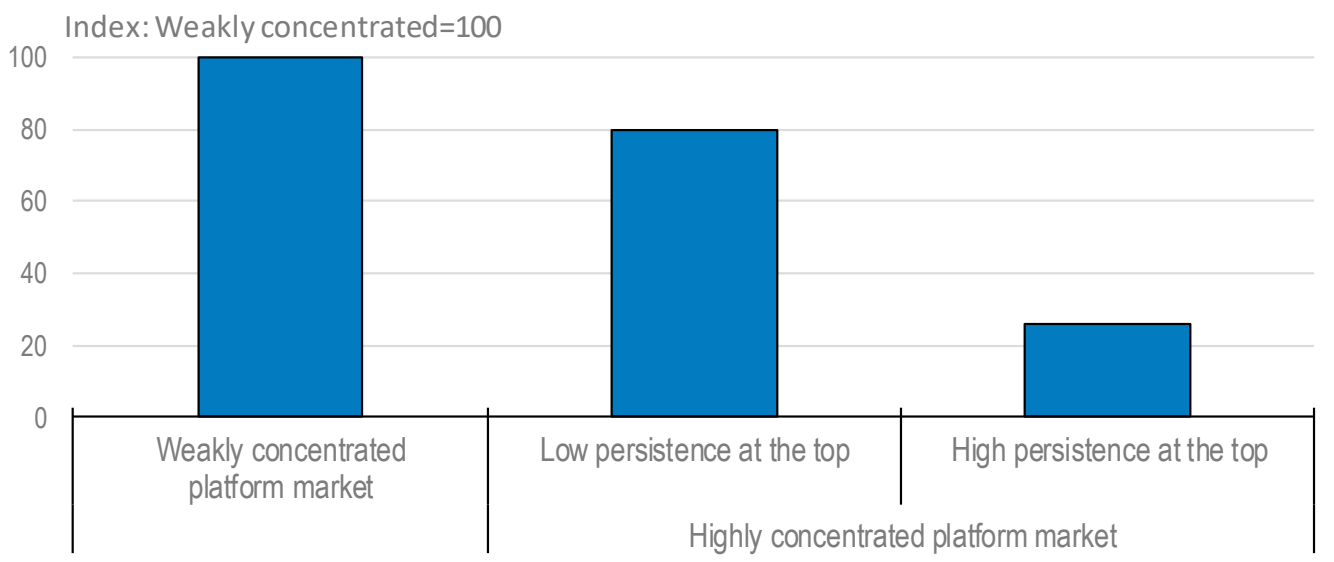

Note: The estimated impact is based on the coefficient estimates in Table 6 (column 2), using the average change in the platform indicator in each country and sector over 2004-16 (see details below Figure 5). Weakly (highly) concentrated indicates that the market share of the largest platform is below (above) the median in the sample. High persistence indicates that the largest platform was already the largest in the two previous years. The first two bars are not statistically different from each other, whereas the third one is significantly lower than the first one.

Source: OECD calculations based on ORBIS and Google Trends.

65. Overall, these results suggest that encouraging both competition on the market and for the market matters for reaping the positive productivity effects of platform development on incumbent service providers. If both are absent, the productivity benefits from the platforms are greatly reduced (Figure 7). This implies that policies to reduce switching costs between platforms (e.g. on data portability, multi-homing, best-price clauses) as well as the merger assessment rules applied to platforms may affect productivity in service sectors.

\subsection{Effect of product and labour market regulations}

66. Regression results also suggest that strict product and labour market regulations can weigh on the productivity of incumbent service providers in an environment where platforms are developing, possibly by hindering their ability to deal with the economic changes induced by platform development (Table 7, Figure 8). In the case of "disruptor" platforms, this means that the effect of platform development on the observed productivity of incumbents can often be negative. ${ }^{29}$

67. Interestingly, the (negative) impact of strict product and labour market regulations is much more pronounced for "disruptor" than "aggregator" platforms. This may reflect

\footnotetext{
${ }^{29}$ In the specification with "disruptors" (Table 7, column 3), the baseline effect of platforms for the average policy stance is negative and significant, while it was slightly positive but not significant in the baseline regression (Table 2). This suggests that the average direction of this effect is difficult to know with certainty, possibly due to different directions across sectors and policy conditions (Table 3).
} 
that the former represent a much stronger competition shock for incumbent service providers than the latter, thereby making their ability to adjust to new market conditions particularly important. For example, existing providers may find it difficult to scale down capacity, including by reducing employment, to adjust to lower demand as new types of providers have attracted some of their consumers. Also, to the extent that existing providers had been sheltered from competition by strict regulation, they may find it more difficult to operate in the new competitive environment. ${ }^{30}$

Table 7. Effect of online platforms on the productivity of existing service providers, effect of product and labour market policies

\begin{tabular}{|c|c|c|c|}
\hline & $\begin{array}{c}\text { (1) } \\
\text { All platforms }\end{array}$ & $\begin{array}{c}(2) \\
\text { Aggregators }\end{array}$ & $\begin{array}{c}(3) \\
\text { Disruptors }\end{array}$ \\
\hline & \multicolumn{3}{|c|}{ Dependent variable: $\Delta M F P_{i, t}$} \\
\hline All platforms $\mathrm{s}_{\mathrm{c}, \mathrm{s}, \mathrm{t}-1}$ & $\begin{array}{c}0.06085^{* * *} \\
(0.015)\end{array}$ & & \\
\hline Aggregators $_{c, s, t-1}$ & & $\begin{array}{c}0.08258^{* * *} \\
(0.016)\end{array}$ & \\
\hline Disruptors $_{c, s, t-1}$ & & & $\begin{array}{c}-0.16212^{* * *} \\
(0.030)\end{array}$ \\
\hline Platforms $_{c, s, t-1} \times P M_{c, t-1}$ & $\begin{array}{c}-0.03958^{*} \\
(0.022)\end{array}$ & $\begin{array}{c}-0.04216 \\
(0.027)\end{array}$ & $\begin{array}{c}-0.28139^{* * *} \\
(0.043)\end{array}$ \\
\hline Platforms $_{c, s, t-1} \times E L_{c, t-1}$ & $\begin{array}{c}-0.05296^{* * *} \\
(0.013)\end{array}$ & $\begin{array}{c}-0.03476^{*} \\
(0.019)\end{array}$ & $\begin{array}{c}-0.05582^{* * *} \\
(0.018)\end{array}$ \\
\hline Firm fix ed effects & YES & YES & YES \\
\hline Country*Year fix ed effects & YES & YES & YES \\
\hline Industry ${ }^{*}$ Year fix ed effects & YES & YES & YES \\
\hline Observations & 701,304 & 701,304 & 701,304 \\
\hline $\mathrm{R} 2$ & 0.171 & 0.171 & 0.171 \\
\hline
\end{tabular}

Note: The equation estimated corresponds to Equation 3. $\triangle \mathrm{MFP}$ is the 1-year multifactor productivity growth of firm $i$ in year $t$, based on Solow residual estimations. PMR denotes the Barriers to entrepreneurship component of the PMR indicator; EPL denotes the Temporary workers component of the EPL indicator. The 3 platform variables correspond to the popularity of (i) all platforms, (ii) "aggregator" platforms (e.g. Booking.com, TheFork), (iii) "disruptors" platforms (e.g. Airbnb, Uber). Industry refers to 4-digit level NACE sectors, namely hotels (5510), restaurants (5610), taxi (4932), retail trade of books (4761), of toys (4765), of shoes (4772), of perfume and cosmetics (4775) and of watches and jewellery (4777). The sample covers BEL, DEU, ESP, FRA, GBR, HUN, ITA, POL, SWE, USA over 2004-2016. Robust standard errors are clustered by firm and by country-industry-year. ${ }^{* * *}$ denotes statistical significance at the $1 \%$ level, ${ }^{* *}$ significance at the $5 \%$ level, * significance at the $10 \%$ level.

Source: OECD calculations based on ORBIS and Google Trends.

30 The effect of sectoral regulation is difficult to assess with existing data. In retail, the effect of regulations (as measured by the retail component of the OECD PMR indicator) was tested but not found to be significant. No similar measure exists for hotels and restaurants, while a sectoral measure for taxis is only available in the 2018 PMR edition, i.e. after the end of the sample period. 


\section{Figure 8. Stricter product and labour market regulations reduce the productivity benefits from platforms}

$\%$ change in multi-factor productivity of the average service firm resulting from raising platform intensity from the average value in 2011 to that in 2017

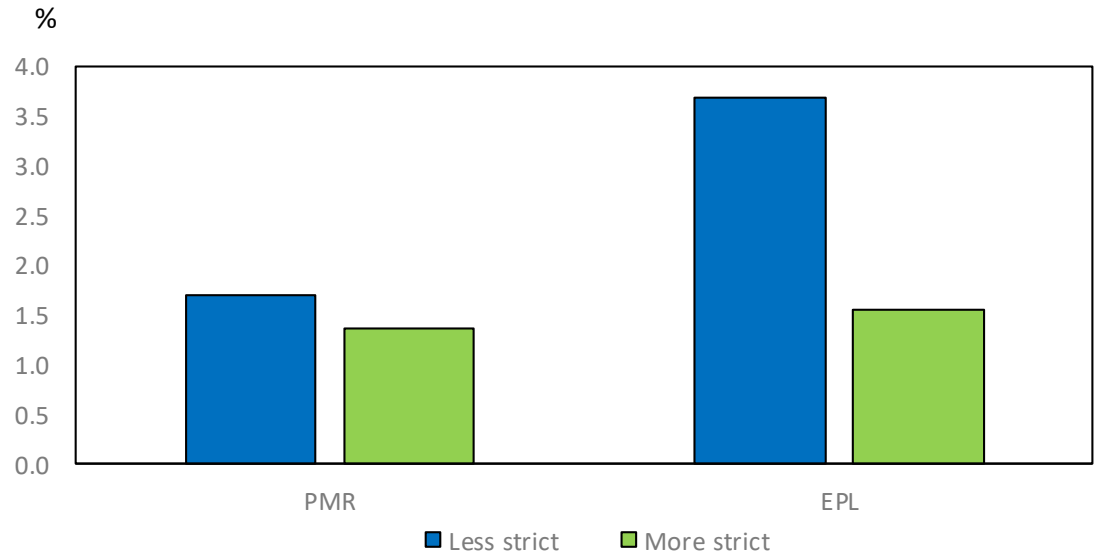

Note: The estimated impact is based on the coefficient estimates in Table 7 (column 1) and on the average change in the platform indicator in each country and sector over 2011-17 (see details below Figure 5). PMR refers to the "barriers to entrepreneurship" component of the OECD PMR indicator. EPL refers to the OECD indicator on employment protection legislation on temporary contracts. The group of countries with less strict (below median) values for PMR on average over the sample is: Germany, UK, Italy, Poland, US; more strict PMR (above median values): Belgium, Spain, Germany, Hungary, Sweden; less stringent EPL (below median): France, UK, Hungary, Sweden, US; more stringent EPL (above median): Belgium, Spain, France, Italy, Poland. Source: OECD calculations based on ORBIS and Google Trends.

\subsection{Identifying country-specific bottlenecks to productivity gains}

68. Summarising these different findings, country-specific structural and policy factors found to influence the impact of platform development are presented in Table 8 . The effect of platforms on the productivity of incumbent service firms is likely to be more positive (i) when platform development is greater (which in itself is likely to be affected by policies, in a way that is not assessed in this study), especially for "aggregator" platforms, (ii) when the platform market is not concentrated or when this concentration is not persistent, and (iii) when relevant product and labour market policies are relatively flexible.

69. This table can help identifying country-specific bottlenecks to a productivityenhancing development of platforms. For example, the United Kingdom has high platform development and flexible product and labour markets, but the high persistence at the top of the largest platforms may reduce the associated productivity gains. In contrast, the main factor hindering productivity gains from platforms in Spain seems to be the strictness of product and labour market regulations (at least based on their 2013 stance). Finally, Germany lags behind in platform development in the sectors considered, while other structural and policy factors (structure of the platform market and product and labour market policies) suggest that it could benefit a lot from it. 
Table 8. Structural and policy factors influencing the impact of platforms on the productivity of existing service providers

Cells shaded in green indicate a more positive effect than for the median country

\begin{tabular}{|c|c|c|c|c|c|c|c|}
\hline & \multicolumn{3}{|c|}{ Platform development (2017) } & \multicolumn{2}{|c|}{$\begin{array}{l}\text { Structure of platform market } \\
\qquad(2017)\end{array}$} & \multicolumn{2}{|c|}{$\begin{array}{l}\text { Product and labour market } \\
\text { policies (2013) }\end{array}$} \\
\hline & Overall & "Aggregators" & "Disruptors" & Concentration & Persistence & $\begin{array}{l}\text { EPL (temporary } \\
\text { contracts) }\end{array}$ & $\begin{array}{l}\text { PMR (barriers to } \\
\text { entrepreneurship) }\end{array}$ \\
\hline Belgium & 0.320 & 0.197 & 0.135 & 0.569 & 0.65 & 2.375 & 1.781 \\
\hline France & 0.473 & 0.219 & 0.300 & 0.631 & 1.00 & 3.625 & 1.684 \\
\hline Germany & 0.251 & 0.170 & 0.156 & 0.549 & 0.75 & 1.125 & 1.664 \\
\hline Hungary & 0.167 & 0.097 & 0.073 & 0.617 & 0.90 & 1.250 & 1.691 \\
\hline Italy & 0.448 & 0.342 & 0.252 & 0.594 & 0.50 & 2.000 & 1.224 \\
\hline Poland & 0.173 & 0.092 & 0.117 & 0.637 & 0.95 & 1.750 & 1.636 \\
\hline Spain & 0.431 & 0.288 & 0.231 & 0.545 & 0.70 & 2.563 & 2.104 \\
\hline Sweden & 0.184 & 0.104 & 0.099 & 0.658 & 1.00 & 0.813 & 1.710 \\
\hline United Kingdom & 0.711 & 0.495 & 0.349 & 0.586 & 1.00 & 0.375 & 1.485 \\
\hline United States & 0.510 & 0.205 & 0.362 & 0.594 & 0.50 & 0.250 & 1.557 \\
\hline
\end{tabular}

Note: Platform development is the unweighted average of platform use across the four sectors considered (hotels, restaurants, taxis and retail, which is itself the unweighted average of five subsectors). It varies between 0 and 1 (a value of 1 would indicate that country has the highest platform development among sample countries in all industries at the same time). The concentration (market share of the largest platform in a sector) and persistence (dummy equal to one when the largest platform was already the largest in the two previous years) indicators are also unweighted averages across sectors in 2017. Employment protection legislation (EPL) on temporary contracts and product market regulation (PMR, "barriers to entrepreneurship" component) correspond both to 2013 data, which is the most recent available. Cells shaded in green indicate a value above/below the median across these ten countries, in a direction suggesting higher productivity effects for incumbent service firms (e.g. low concentration, or low PMR). No cell is shaded for "disruptor" platforms since their average effect on incumbents' productivity is not significant. The sum of "aggregator" and "disruptor" platform can be higher than the "overall" platform indicator, reflecting that certain platforms as included in both categories.

Source: OECD calculations

\subsection{How do platforms impact profits, employment and wages?}

70. The impact of platforms on other characteristics of incumbent service firms (markups, profit rates, employment and real wage per employee) are explored using the same regression framework as for productivity (Equation 1). The results are more tentative and generally smaller than for productivity, but they confirm that different platform types have very different effects (Table 9). 
Table 9. The impact of platform use on profitability and labour

Panel A: Mark-ups and profit rates

\begin{tabular}{|c|c|c|c|c|c|c|}
\hline & \multicolumn{6}{|c|}{ Dependent variable } \\
\hline & \multicolumn{3}{|c|}{$\Delta$ Markup $_{i, t}$} & \multicolumn{3}{|c|}{$\Delta$ ProfitRate $_{i, t}$} \\
\hline All platforms $\mathrm{c}_{\mathrm{c}, \mathrm{s}, \mathrm{t}-1}$ & $\begin{array}{c}-0.00235 \\
(0.004)\end{array}$ & & & $\begin{array}{c}0.01276^{\star * \star} \\
(0.004)\end{array}$ & & \\
\hline Aggregators $_{\mathrm{c}, \mathrm{s}, \mathrm{t}-1}$ & & $\begin{array}{c}0.00907^{* *} \\
(0.004)\end{array}$ & & & $\begin{array}{r}0.01984^{* * *} \\
(0.004)\end{array}$ & \\
\hline Disruptors $_{\mathrm{c}, \mathrm{s}, \mathrm{t}-1}$ & & & $\begin{array}{c}-0.01245^{\star *} \\
(0.006)\end{array}$ & & & $\begin{array}{c}-0.00003 \\
(0.005) \\
\end{array}$ \\
\hline Firm fixed effects & YES & YES & YES & YES & YES & YES \\
\hline Country*Year fixed effects & YES & YES & YES & YES & YES & YES \\
\hline Industry*Year fixed effects & YES & YES & YES & YES & YES & YES \\
\hline Observations & 431,211 & 431,211 & 431,211 & 431,211 & 431,211 & 431,211 \\
\hline R-squared & 0.171 & 0.171 & 0.171 & 0.146 & 0.146 & 0.145 \\
\hline F-statistic & 0.348 & 4.787 & 4.795 & 12.46 & 27.93 & 0.00003 \\
\hline
\end{tabular}

Panel B: Wages and employment

\begin{tabular}{|c|c|c|c|c|c|c|}
\hline & \multicolumn{6}{|c|}{ Dependent variable } \\
\hline & & $\Delta$ Wages $_{i, t}$ & & & Employmen & \\
\hline All platforms $\mathrm{c}_{\mathrm{c}, \mathrm{s}, \mathrm{t}-1}$ & $\begin{array}{c}-0.00009 \\
(0.012)\end{array}$ & & & $\begin{array}{c}0.01967^{*} \\
(0.012)\end{array}$ & & \\
\hline Aggregators $_{\mathrm{c}, \mathrm{s}, \mathrm{t}-1}$ & & $\begin{array}{c}0.00354 \\
(0.013)\end{array}$ & & & $\begin{array}{c}0.03296^{* * *} \\
(0.012)\end{array}$ & \\
\hline Disruptors $_{\mathrm{c}, \mathrm{s}, \mathrm{t}-1}$ & & & $\begin{array}{c}-0.03309^{*} \\
(0.018) \\
\end{array}$ & & & $\begin{array}{c}-0.03256^{* *} \\
(0.017) \\
\end{array}$ \\
\hline Firm fixed effects & YES & YES & YES & YES & YES & YES \\
\hline Country*Year fixed effects & YES & YES & YES & YES & YES & YES \\
\hline Industry*Year fixed effects & YES & YES & YES & YES & YES & YES \\
\hline Observations & 431,211 & 431,211 & 431,211 & 431,211 & 431,211 & 431,211 \\
\hline R-squared & 0.173 & 0.173 & 0.173 & 0.190 & 0.190 & 0.190 \\
\hline F-statistic & 0.00005 & 0.0767 & 3.568 & 2.884 & 7.508 & 3.892 \\
\hline
\end{tabular}

Note: Platform variables refer to the Google Trends-based indicator of the intensity of use of all platforms, "aggregator" platforms, or "disruptor" platforms. The equation estimated is similar to Equation 1, with alternative dependent variables. Mark-ups are measured by the log of the mark-ups obtained by the De Loecker and Warzynski methodology, assuming the intermediate input choice is fully flexible. Profit rates are the ratio of profits (EBITDA) to revenues. Employment and real average wages (wage bill per employment, deflated by industry level output deflators) are measured in logs. Industry refers to 4-digit level NACE sectors, namely hotels (5510), restaurants (5610), taxi (4932), retail trade of books (4761), of toys (4765), of shoes (4772), of perfume and cosmetics (4775) and of watches and jewellery (4777). The sample covers BEL, DEU, ESP, FRA, GBR, HUN, ITA, POL, SWE, USA over 2004-2016. Robust standard errors are clustered by firm and at the country-industry-year level. *** denotes statistical significance at the $1 \%$ level, ${ }^{* *}$ significance at the $5 \%$ level, * significance at the $10 \%$ level.

Source: OECD calculations based on ORBIS and Google Trends.

71. "Aggregator" platforms, which have already been found to stimulate productivity, also support mark-ups, profits and employment of service firms in the selected industries, while they have no significant effect on wages. This suggests that the productivity gains achieved by service providers thanks to platform development are used both to scale up and raise profits, although these effects are substantially smaller than the ones on productivity, presented in Table 2. These increases may also result from higher overall demand for services thanks to platform development (more consumers are likely to buy services in the presence of a platform reducing information asymmetries). Interestingly, mark-ups are increased despite the additional competitive pressures induced by platforms (which all else equal would be expected to reduce mark-ups). 
72. "Disruptor" platforms, which have no significant effect on the average productivity of existing providers, are found to reduce their mark-ups, employment and wages. This may reflect that demand for services is partly redirected towards the new alternative providers enabled by these platforms, implying that existing providers face lower demand. They adjust employment downwards, which allows them to avoid productivity losses, but also have to reduce real wages and mark-ups due to the increased competitive pressures.

73. These results are robust for most of the sectors taken individually, but mainly driven by hotels and restaurants (Table 10). In particular, mark-ups, profit rates and wages respond positively for hotels exposed to an intensive use of aggregator platforms. The same holds for profit rates and employment in the case of restaurants. Widespread development of disruptor platforms, on the other hand, is associated with negative changes in all four outcome variables for hotels - and for the case of taxis, in wages. For retail subsectors, the impacts are not significant, probably reflecting the difficulty in differentiating between positive effects of aggregators and negative effects of disruptors, given the predominance of mixed-type platforms in that sector.

Table 10. The impact of platform use on profitability and labour by sectors

Panel A: Aggregator platforms

\begin{tabular}{lcccc} 
& Markups & Profit Rate & Wages & Employment \\
\hline Hotels & $0.04^{\star * *}$ & $0.038^{* * *}$ & $0.068^{* * *}$ & -0.015 \\
Restaurants & 0.009 & $0.048^{* * *}$ & 0.015 & $0.323^{\star * *}$ \\
Taxi & na & na & na & na \\
Retail subsectors & -0.008 & 0.01 & -0.013 & -0.037 \\
\hline \hline
\end{tabular}

Panel B: Disruptor platforms

\begin{tabular}{lcccc} 
& Markups & Profit Rate & Wages & Employment \\
\hline Hotels & $-0.119^{* * *}$ & $-0.052^{* * *}$ & $-0.136^{* * *}$ & $-0.079^{* *}$ \\
Restaurants & na & na & na & na \\
Taxi & -0.113 & -0.046 & $-0.574^{* *}$ & -0.238 \\
Retail subsectors & -0.008 & 0.009 & -0.019 & -0.037 \\
\hline \hline
\end{tabular}

Note: Platform variables refer to the Google Trends-based indicator of the intensity of use of all platforms, "aggregator" platforms, or "disruptor" platforms. The equation estimated is similar to Equation 1, with alternative dependent variables. Mark-ups are measured by the log of the mark-ups obtained by the De Loecker and Warzynski methodology, assuming the intermediate input choice is fully flexible. Profit rates are the ratio of profits (EBITDA) to revenues. Employment and real average wages (wage bill per employment, deflated by industry level output deflators) are measured in logs. Industry refers to 4-digit level NACE sectors, namely hotels (5510), restaurants (5610), taxi (4932), retail trade of books (4761), of toys (4765), of shoes (4772), of perfume and cosmetics (4775) and of watches and jewellery (4777). The sample covers BEL, DEU, ESP, FRA, GBR, HUN, ITA, POL, SWE, USA over 2004-2016. Robust standard errors are clustered by firm and at the country-industry-year level. *** denotes statistical significance at the $1 \%$ level, ${ }^{* *}$ significance at the $5 \%$ level, * significance at the $10 \%$ level. Some cells are filled with ' $n a$ ' because all platforms in the restaurants sector are Aggregators, while Aggregators are absent in most countries in the taxi sector.

Source: OECD calculations based on ORBIS and Google Trends.

\section{Conclusion and key policy implications}

74. This paper sheds light on the effect of online platform development on the productivity of incumbent service firms, which is a step in the direction of assessing the economy-wide productivity implications of platforms. The results suggest that online 
platforms have the potential to increase productivity, both by stimulating the productivity of incumbent service firms in the selected industries and promoting an efficient reallocation of labour towards the more productive of them. These results mainly come from "aggregator" platforms that connect consumers to existing service providers and may reduce information asymmetries between them thanks to review and rating systems. These productivity gains translate into slightly higher mark-ups and profits for service providers, and also allow them to increase employment. In contrast, the more disruptive platforms enabling new types of service providers do not affect the productivity of incumbents in a systematic way, but tend to reduce moderately their mark-ups, wages and employment.

75. These results have implications for policies related to platforms and the industries where they operate. The fact that platforms can stimulate the productivity of service providers is one of the dimensions that should be considered when designing policies applying to platforms, along with other relevant dimensions, such as consumer protection, data privacy, taxation and labour relations.

76. The productivity gains from platforms are reduced when competition between platforms is weak both on the market (as measured by the market share of the largest platform in an industry) and for the market (as measured by a proxy of the persistence of the largest platform at the top). Since platform markets have a tendency to be concentrated due to very strong network effects, policies should aim at reducing switching costs between platforms, both for consumers and service providers. This can involve facilitating data transferability across platforms (e.g. reputation, rating) and forbidding contractual clauses that discourage multi-homing (using several platforms at the same time) as well as bestprice clauses that discourage use of alternative platforms. Strict enforcement of competition policy tools is also warranted, while the competition implications of multi-sided network effects should be further investigated (OECD, 2018 $[54]) .{ }^{31}$

77. The productivity gains from aggregator platforms are also found to be reduced by the presence of strict product and labour market regulations (e.g. administrative burdens, employment protection). This may be because such regulations hinder the flexibility of service providers to adjust to the economic changes induced by platforms. More broadly, the current situation calls for reassessing certain regulations to take into account the existence of platforms. For example, certain product market regulations meant to address information asymmetries between service providers and suppliers (e.g. occupational licensing requirements, quality standards) have become obsolete as platforms offer more efficient ways to address these asymmetries. While safety and consumer protection should not be jeopardised, there may be room to lighten some of these regulations, which could reduce barriers to entry to certain activities and support productivity.

78. A difficult question is how to regulate the new activities that platforms enable (e.g. home-sharing, ride-hailing) and that compete to some extent with existing services. These new providers can bring efficiency-enhancing features (e.g. efficient matching, better use of spare capacities, including by non-professional providers), but their success may also reflect to some extent the lighter regulation and taxation that they face in many countries. While a regulatory light touch is warranted in the short term to stimulate innovation (e.g.

\footnotetext{
${ }^{31}$ Platforms typically benefit at the same time from network effects (i) on the consumer side (more consumers make the platform more attractive to service providers), (ii) on the service provider side (more providers make the platform more attractive to consumers) and (iii) in terms of data (more consumers and more data from transactions help platforms improve their algorithms and ratings, thereby enhancing the quality of their service).
} 
with "sandbox" schemes), in the longer term policy-makers should aim at levelling the playing field between the providers of services that compete with each other, and therefore gradually subject new types of providers to tax and regulatory rules of equivalent strictness as those faced by the incumbents.

79. To shed further light on these issues, future research in the area of online platforms could make use of the indicator of platform development built in this paper. This indicator could be compiled for more countries beyond the ten selected in this paper. One question that could be explored is what determines platform development across industries and countries, and more specifically what is the influence of policy settings. For example, the fact that certain industries are strictly regulated in certain countries may have supported the development of platforms enabling alternative providers that did not face the same tax rules or regulatory constraints (e.g. Uber vs. taxis). Better understanding this would help assessing to what extent platforms' popularity reflect the efficiency gains they bring or the regulatory environment they face. 


\section{References}

Adalet McGowan, M., D. Andrews and V. Millot (2017), "Insolvency regimes, zombie firms and capital reallocation", OECD Economics Department Working Papers, No. 1399, OECD Publishing, Paris, https://dx.doi.org/10.1787/5a16beda-en.

Aghion, P. and P. Howitt (1998), Endogenous growth theory, The MIT Press.

Aguiar, L. and J. Waldfogel (2018), "Platforms, Promotion, and Product Discovery: Evidence from Spotify Playlists", NBER Working Paper, No. 24713, http://www.nber.org/papers/w24713.

Anderson, M. and J. Magruder (2012), "Learning from the Crowd: Regression Discontinuity Estimates of the Effects of an Online Review Database", Economic Journal, Vol. 122, pp. 957-989, http://dx.doi.org/10.1111/j.1468-0297.2012.02512.x.

Andrews, D., C. Criscuolo and P. Gal (2016), "The Best versus the Rest: The Global Productivity Slowdown, Divergence across Firms and the Role of Public Policy", OECD Productivity Working Papers, No. 5, OECD Publishing, Paris, https://dx.doi.org/10.1787/63629cc9-en.

Askitas, N. and K. Zimmermann (2009), "Google Econometrics and Unemployment Forecasting", IZA Discussion Papers, No. 4201, Institute for the Study of Labor (IZA), Bonn, http://hdl.handle.net/10419/35733www.econstor.eu.

Atkin, D., A. Khandelwal and A. Osman (2019), "Measuring Productivity: Lessons from Tailored Surveys and Productivity Benchmarking", NBER Working Papers, No. 25471, National Bureau of Economic Research, Cambridge, MA, http://dx.doi.org/10.3386/w25471.

Bajgar, M., C. Criscuolo and J. Timmis (2019), Mergers and Acquisitions, Concentration and Productivity: What do we know so far?, OECD Productivity Working Papers, forthcoming.

Berger, T., C. Chen and C. Frey (2018), "Drivers of disruption? Estimating the Uber effect", European Economic Review, Vol. 110, pp. 197-210, http://dx.doi.org/10.1016/j.euroecorev.2018.05.006.

Calabrese, A. (2012), "Service productivity and service quality: A necessary trade-off?", International Journal of Production Economics, Vol. 135/2, pp. 800-812, http://dx.doi.org/10.1016/J.IJPE.2011.10.014.

Calvano, E. et al. (2018), "Artificial intelligence, algorithmic pricing and collusion", Discussion Paper, No. DP13405, Center for Economic Policy Research, https://cepr.org/active/publications/discussion_papers/dp.php?dpno=13405\#.

Cameron, A., J. Gelbach and D. Miller (2011), "Robust Inference With Multiway Clustering", Source: Journal of Business \& Economic Statistics, Vol. 29/2, pp. 238-249, http://dx.doi.org/10.1198/jbes.2010.07136. 
Carrière-Swallow, Y. et al. (2013), "Nowcasting with Google Trends in an Emerging Market", Journal of Forecasting, Vol. 32/4, pp. 289-298, https://econpapers.repec.org/article/wlyjforec/v_3a32_3ay_3a2013 3ai_3a4_3ap_3a289298.htm.

Choi, H. and H. Varian (2012), "Predicting the Present with Google Trends", Economic Record, Vol. 88, pp. 2-9, http://dx.doi.org/10.1111/j.1475-4932.2012.00809.x.

Cramer, J. and A. Krueger (2016), "Disruptive Change in the Taxi Business: The Case of Uber", NBER Working Paper, No. 22083, http://www.nber.org/papers/w22083.

D’Amuri, F. and J. Marcucci (2010), ““'Google it!”Forecasting the US Unemployment Rate with a Google Job Search index”, Fondazione Eni Enrico Mattei Working Papers, No. 2010.31, https://ideas.repec.org/p/fem/femwpa/2010.31.html.

Dai, W. et al. (2014), "Aggregation of Consumer Ratings: An Application to Yelp.com", NBER Working Paper, No. 18567, https://www.nber.org/papers/w18567.pdf.

De Loecker, J. and F. Warzynski (2012), Markups and firm-level export status, http://dx.doi.org/10.1257/aer.102.6.2437.

Decker, R. et al. (2017), Declining dynamism, allocative efficiency, and the productivity slowdown, http://dx.doi.org/10.1257/aer.p20171020.

Decker, R. et al. (2016), Declining Business Dynamism: Implications for Productivity?, https://www.brookings.edu/wp-content/uploads/2016/08/haltiwanger_conference draft.pdf.

Della Penna, N. and H. Huang (2009), "Constructing Consumer Sentiment Index for U.S. Using Google Searches", University of Alberta, Department of Economics Working Papers, No. 2009-26, https://ideas.repec.org/p/ris/albaec/2009 026.html.

Feyrer, J., E. Mansur and B. Sacerdote (2017), "Geographic dispersion of economic shocks: Evidence from the fracking revolution", American Economic Review, Vol. 107/4, http://dx.doi.org/10.1257/aer.20151326.

Filippas, A., J. Horton and J. Golden (2018), Reputation Inflation, NYU Stern School of Business, http://john-joseph-horton.com/papers/longrun.pdf.

Foster, L., C. Grim and J. Haltiwanger (2016), "Reallocation in the Great Recession: Cleansing or $[50]$ Not?", Journal of Labor Economics, Vol. 34 https://www.journals.uchicago.edu/doi/abs/10.1086/682397.

Fradkin, A., E. Grewal and D. Holtz (2018), The Determinants of Online Review Informativeness: Evidence from Field Experiments on Airbnb, https://andreyfradkin.com/assets/reviews paper.pdf.

French government (2017), Mémento du Toursime, https://www.entreprises.gouv.fr/files/files/directions_services/etudes-et-statistiques/statstourisme/memento/2017/2017-11-MEMENTO-TOURISME-CHAP4-la-frequentationhebergements.pdf. 
Gal, P. (2013), "Measuring Total Factor Productivity at the Firm Level using OECD-ORBIS",

OECD Economics Department Working Papers, No. 1049, https://www.oecd-

ilibrary.org/economics/measuring-total-factor-productivity-at-the-firm-level-using-oecdorbis $5 \mathrm{k} 46 \mathrm{dsb} 25 \mathrm{ls} 6$-en.

Gal, P. and A. Hijzen (2016), "The short-term impact of product market reforms: A cross-country firm-level analysis", IMF Working Paper, N16/116.

Graevenitz, G. et al. (2016), "Does Online Search Predict Sales? Evidence from Big Data for Car Markets in Germany and the UK", Queen Mary, University of London, School of Business and Management, Centre for Globalisation Research Working Papers, No. 71.

Harris, S. and A. Krueger (2015), "A Proposal for Modernizing Labor Laws for Twenty-FirstCentury Work: The "Independent Worker"', Hamilton Project Discussion Paper, No. 2015/10, http://www.hamiltonproject.org/assets/files/modernizing labor_laws for twenty first century work_krueger_harris.pdf.

Horton, J. and J. Golden (2015), "Reputation Inflation in an Online Marketplace", https://pdfs.semanticscholar.org/b90a/f87887292b1241db6dd4d698a3527f2b5d99.pdf.

Hui, X. et al. (2016), "Reputation and Regulations: Evidence from eBay", Management Science, Vol. 62/12, http://dx.doi.org/10.1287/mnsc.2015.2323.

Hunold, M. et al. (2018), "Evaluation of best price clauses in online hotel bookings", International Journal of Industrial Organization, Vol. 61, pp. 542-571, http://dx.doi.org/10.1016/J.IJINDORG.2018.03.008.

Kalemli-Ozcan, S. et al. (2015), "How to Construct Nationally Representative Firm Level data from the ORBIS Global Database", BNER Working Papers, No. 21558, http://dx.doi.org/10.3386/w21558.

Klein, T., C. Lambertz and K. Stahl (2016), "Market Transparency, Adverse Selection, and Moral Hazard", Journal of Political Economy, Vol. 124/6, https://www.journals.uchicago.edu/doi/pdfplus/10.1086/688875.

Li, L., S. Tadelis and X. Zhou (2016), "Buying Reputation as a Signal of Quality: Evidence from an Online Marketplace", NBER Working Paper, No. 22584, http://www.nber.org/papers/w22584.pdf.

Liu, M., E. Brynjolfsson and J. Dowlatabadi (2018), "Do digital platforms reduce moral hazard? The case of Uber and taxis", NBER Working Papers, No. 25015, http://www.nber.org/papers/w25015.

Luca, D. and M. Luca (2019), "Survival of the fittest: The impact of the minimum wage on firm exit", NBER Working Paper, No. 25806, http://www.nber.org/papers/w25806.

Luca, M. (2017), "Designing Online Marketplaces: Trust and Reputation Mechanisms", Innovation Policy and the Economy, Vol. 17, pp. 77-93, http://dx.doi.org/10.1086/688845. 
Luca, M. and G. Zervas (2016), "Fake It Till You Make It: Reputation, Competition, and Yelp Review Fraud", Management Science, Vol. 62/12, http://dx.doi.org/10.1287/mnsc.2015.2304.

Mayzlin, D., Y. Dover and J. Chevalier (2014), "Promotional Reviews: An Empirical Investigation of Online Review Manipulation", American Economic Review, Vol. 104/8, pp. 2421-2455, http://dx.doi.org/10.1257/aer.104.8.2421.

Nickell, S. (1981), "Biases in Dynamic Models with Fixed Effects", Econometrica, Vol. 49/6, p. 1417, http://dx.doi.org/10.2307/1911408.

Nosko, C. and S. Tadelis (2015), "The limits of reputation in platform markets: An empirical analysis and field experiment", NBER Working Paper, No. 20830, http://www.nber.org/papers/w20830.

OECD (2019), “An Introduction to Online Platforms and Their Role in the Digital Transformation", forthcoming.

OECD (2018), "Measuring online platforms and cloud computing in National Accounts", report prepared for WPMADE November meeting,, No. DSTI/CDEP/MADE(2018)6, https://one.oecd.org/document/DSTI/CDEP/MADE(2018)6/en/pdf.

OECD (2018), "Personalised Pricing in the Digital Era", Background Note by the OECD Secretariat, http://www.oecd.org/daf/competition/personalised-pricing-in-the-digital-era.htm.

OECD (2018), Rethinking Antitrust Tools for Multi-Sided Platforms, http://www.oecd.org/competition/rethinking-antitrust-tools-for-multi-sided-platforms.htm.

OECD (2017), Algorithms and collusion: Competition policy in the digital age, http://www.oecd.org/daf/competition/Algorithms-and-colllusion-competition-policy-in-thedigital-age.pdf.

OECD (2017), "Trust in peer platform markets: Consumer survey findings", OECD Digital Economy Papers, No. 263, http://dx.doi.org/10.1787/20716826.

Preis, T., H. Moat and H. Stanley (2013), "Quantifying Trading Behavior in Financial Markets Using Google Trends”, Scientific Reports, Vol. 3, p. 1684, http://dx.doi.org/10.1038/srep01684.

Rayle, L. et al. (2015), "Just a better taxi? A survey-based comparison of taxis, transit, and ridesourcing services in San Francisco", Transport Policy, Vol. 45, pp. 168-178, http://dx.doi.org/10.1016/j.tranpol.2015.10.004.

Reimsbach-Kounatze, C. (2015), "The Proliferation of "Big Data" and Implications for Official Statistics and Statistical Agencies: A Preliminary Analysis", OECD Digital Economy Papers, No. 245, https://ideas.repec.org/p/oec/stiaab/245-en.html.

Resnick, P. et al. (2006), "The value of reputation on eBay: A controlled experiment", Experimental Economics, Vol. 9/2, pp. 79-101, http://dx.doi.org/10.1007/s10683-006-4309-2. 
Robin, F. (2018), "Use of Google Trends Data in Banque de France Monthly Retail Trade Survey", Economie et Statistique / Economics and Statistics 505-506, pp. 35-63, https://doi.org/10.24187/ecostat.2018.505d.1965.

Schwellnus, C. et al. (2019), "Gig economy platforms: Boon or bane?”, OECD Economics Department Working Papers, No. 1550, OECD Publishing, Paris.

Siliverstovs, B. and D. Wochner (2018), "Google Trends and reality: Do the proportions match?: Appraising the informational value of online search behavior: Evidence from Swiss tourism regions", Journal of Economic Behavior \& Organization, Vol. 145, pp. 1-23, http://dx.doi.org/10.1016/J.JEBO.2017.10.011.

Sorbe, S., P. Gal and V. Millot (2018), "Can productivity still grow in services based economies? Literature overview and preliminary evidence from OECD countries", Economics Department Working Papers, No. 1531, OECD Publishing, Paris, http://dx.doi.org/10.1787/4458ec7b-en.

Tadelis, S. (2016), "Reputation and Feedback Systems in Online Platform Markets", Annual Review of Economics, Vol. 8, pp. 321-340, http://dx.doi.org/10.1146/annurev-economics$\underline{080315-015325 .}$.

Wooldridge, J. (2009), “On estimating firm-level production functions using proxy variables to control for unobservables", Economics Letters, http://dx.doi.org/10.1016/j.econlet.2009.04.026. 


\section{Annex A. Additional information on the platform indicator and descriptive statistics}

Table A.1. Detailed list of platforms included in the analysis

\begin{tabular}{|c|c|c|c|c|}
\hline & Hotels & Restaurants & Taxi & Retail subsectors \\
\hline Aggregators & $\begin{array}{c}\text { Abritel } \\
\text { Atrapalo } \\
\text { Bedandbreakfast.com } \\
\text { Booking.com } \\
\text { Expedia } \\
\text { Flipkey } \\
\text { Homelidays } \\
\text { Hosterworld } \\
\text { Hotels.com } \\
\text { Hoteltonight } \\
\text { Housetrip } \\
\text { Tripadvisor } \\
\text { Trivago } \\
\text { VRBO }\end{array}$ & $\begin{array}{c}\text { Deliveroo } \\
\text { Deliveryhero } \\
\text { Doordash } \\
\text { Eatstreet } \\
\text { Foodora } \\
\text { Foodpanda } \\
\text { Grubhub } \\
\text { Hungryhouse } \\
\text { Justeat } \\
\text { Netpincer } \\
\text { Opentable } \\
\text { Pizzaportal } \\
\text { Takeway.com } \\
\text { Thefork } \\
\text { Tripadvisor } \\
\text { Ubereats } \\
\text { Urbanspoon } \\
\text { Wolt } \\
\text { Yelp } \\
\text { Zomato }\end{array}$ & $\begin{array}{l}\text { Easytaxi } \\
\text { Kabbee }\end{array}$ & Aliexpress \\
\hline Disruptors & $\begin{array}{c}\text { Airbnb } \\
\text { Atraveo } \\
\text { Couchsurfing } \\
\text { Wimdu }\end{array}$ & - & $\begin{array}{c}\text { Cabify } \\
\text { Chauffeurprive } \\
\text { Lecab } \\
\text { Lyft } \\
\text { Mytaxi } \\
\text { Taxify } \\
\text { Uber }\end{array}$ & $\begin{array}{l}\text { Bestbuy } \\
\text { Bookline }\end{array}$ \\
\hline Mixed & Homeaway & - & - & $\begin{array}{c}\text { Amazon } \\
\text { Asos } \\
\text { Ebay } \\
\text { Flipkart } \\
\text { Zalando }\end{array}$ \\
\hline
\end{tabular}

Note: The classification of platforms as aggregators, disruptors or both ("mixed") is based on a qualitative assessment of the business model of each platform and of what constitutes its primary activity over the sample period in the countries considered. Some platforms may belong to the same corporate group (e.g. Abritel, Homelidays and VRBO), which does not affect the construction of the platform use indicator, but may bias downwards the indicator of platform market concentration.

Source: OECD 


\section{Figure A.1. Indicator of platform use}

Hotels
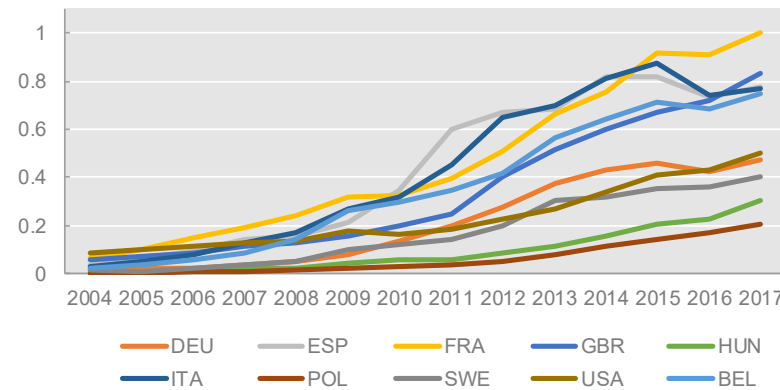

Retail subsectors

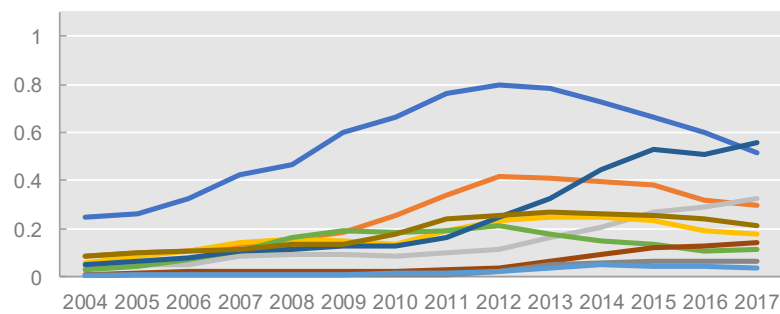

- $\mathrm{DEU}-\mathrm{ESP} \longrightarrow \mathrm{FRA}-\mathrm{GBR}-\mathrm{HUN}$
Restaurants

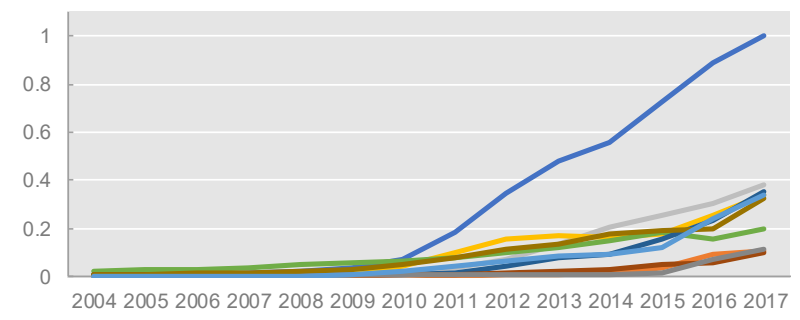

$\longrightarrow \mathrm{DEU} \longrightarrow \mathrm{ESP} \longrightarrow \mathrm{FRA} \longrightarrow \mathrm{GBR} \longrightarrow \mathrm{HUN}$

Taxi services

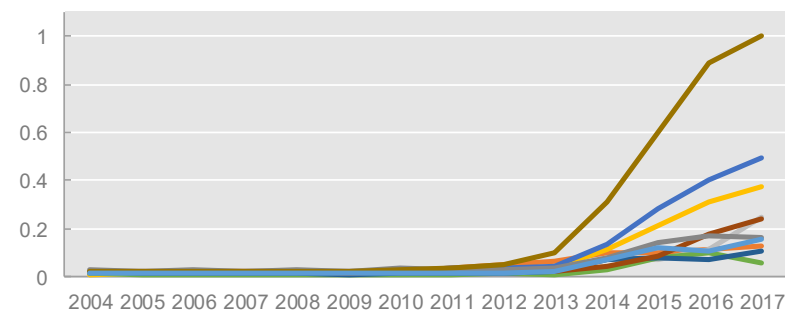

$\longrightarrow \mathrm{DEU} \longrightarrow \mathrm{ESP} \longrightarrow \mathrm{FRA} \longrightarrow \mathrm{GBR} \longrightarrow \mathrm{HUN}$

Note: Retail corresponds to the unweighted average of the five retail subsectors included in the analysis (books, shoes, cosmetics/perfumes, watches/jewellery, and toys).

Source: OECD calculations based on Google Trends. 


\section{Table A.2. Descriptive statistics on the final firm-level sample}

Panel A. Number of observations in the sample by sector

\begin{tabular}{|c|c|}
\hline Hotels & 154,117 \\
\hline Restaurants & 454,843 \\
\hline Taxi services & 22,852 \\
\hline Retail subsectors & 113,100 \\
\hline Books & 15,244 \\
\hline Toys & 9,985 \\
\hline Shoes & 35,691 \\
\hline Perfume and cosmetics & 20,212 \\
\hline Watches and jewellery & 31,968 \\
\hline
\end{tabular}

Panel B. Descriptive statistics of the main variables used in the analysis, in levels

\begin{tabular}{lcccccc} 
& Employment & $\begin{array}{c}\text { Labour } \\
\text { productivity }\end{array}$ & $\begin{array}{c}\text { MFP } \\
\text { (Solow } \\
\text { residual) }\end{array}$ & $\begin{array}{c}\text { MFP } \\
\text { (Wooldridge) }\end{array}$ & $\begin{array}{c}\text { MFP } \\
\text { (Wooldridge, } \\
\text { gross output } \\
\text { based) }\end{array}$ & $\begin{array}{c}\text { Markup } \\
\text { corrected MFP }\end{array}$ \\
\hline 10th percentile & 1.0 & 9.574 & 5.129 & 9.174 & 6.829 & 7.094 \\
90th percentile & 25.0 & 11.043 & 6.919 & 10.740 & 9.846 & 11.131 \\
Mean & 28.2 & 10.328 & 6.014 & 9.977 & 8.557 & 9.447 \\
Median & 5.0 & 10.356 & 6.006 & 10.007 & 8.997 & 10.190 \\
Standard & 653.391 & 0.634 & 0.745 & 0.666 & 1.196 & 1.648 \\
deviation & 692,120 & 727,686 & 744,912 & 735,306 & 702,552 & 523,161 \\
\hline Number of & & & & & & \\
observations & &
\end{tabular}

Panel C. Descriptive statistics of the main variables used in the analysis, in growth rates

\begin{tabular}{|c|c|c|c|c|c|c|c|c|c|}
\hline & Employment & $\begin{array}{c}\text { Labour } \\
\text { productivity }\end{array}$ & $\begin{array}{c}\text { MFP } \\
\text { (Solow } \\
\text { residual) }\end{array}$ & $\begin{array}{c}\text { MFP } \\
\text { (Wooldridge) }\end{array}$ & $\begin{array}{c}\text { MFP } \\
\text { (Wooldridge, } \\
\text { gross output } \\
\text { based) }\end{array}$ & $\begin{array}{c}\text { Markup } \\
\text { corrected MFP }\end{array}$ & Markup & Profit rate & $\begin{array}{c}\text { Real } \\
\text { wages }\end{array}$ \\
\hline 10th percentile & -0.288 & -0.429 & -0.412 & -0.369 & -0.185 & -0.231 & -0.093 & -0.090 & -0.287 \\
\hline 90th percentile & 0.288 & 0.463 & 0.445 & 0.405 & 0.200 & 0.251 & 0.087 & 0.086 & 0.331 \\
\hline Mean & 0.005 & 0.010 & 0.020 & 0.014 & 0.006 & 0.007 & -0.002 & -0.002 & 0.017 \\
\hline Median & 0.000 & 0.000 & 0.022 & 0.005 & 0.001 & 0.001 & 0.000 & -0.002 & 0.008 \\
\hline $\begin{array}{l}\text { Standard } \\
\text { deviation }\end{array}$ & 0.257 & 0.412 & 0.403 & 0.368 & 0.177 & 0.219 & 0.097 & 0.082 & 0.280 \\
\hline $\begin{array}{l}\text { Number of } \\
\text { observations }\end{array}$ & 640,751 & 727,686 & 744,912 & 735,306 & 701,761 & 522,084 & 526,518 & 657,554 & 652,478 \\
\hline
\end{tabular}

Note: The sample is restricted to those observations where the growth rate of our benchmark productivity measure (MFP, Solow residual) and the platform use indicators are available. Growth rates are measured by annual difference in logs.

Source: Calculations using the Orbis database. 


\section{Annex B. Detailed regression results and robustmess checks}

Table B.1. Effect of online platforms on the productivity of existing service providers, alternative specifications

\begin{tabular}{|c|c|c|c|c|c|c|}
\hline & (1) & (2) & (3) & (4) & (5) & (6) \\
\hline Dependent variable: & \multicolumn{3}{|c|}{$\Delta M F P_{i, t}$} & \multicolumn{3}{|c|}{$M F P_{i, t}$} \\
\hline \multirow[t]{2}{*}{$\mathrm{MFP}_{\mathrm{i}, \mathrm{t}-1}$} & $-0.16113^{* * *}$ & $-0.16116^{* * *}$ & $-0.16109^{* * *}$ & & & \\
\hline & $(0.004)$ & $(0.004)$ & $(0.004)$ & & & \\
\hline \multirow[t]{2}{*}{ All platforms $\mathrm{s}_{\mathrm{c}, \mathrm{s}, \mathrm{t}-1}$} & 0.01967 & & & 0.05910 & & \\
\hline & $(0.012)$ & & & $(0.036)$ & & \\
\hline \multirow[t]{2}{*}{ Aggregators $_{\mathrm{c}, \mathrm{s}, \mathrm{t}-1}$} & & $0.03801^{* \star *}$ & & & $0.07645^{\star *}$ & \\
\hline & & $(0.013)$ & & & $(0.035)$ & \\
\hline \multirow[t]{2}{*}{ Disruptors $_{c, s, t-1}$} & & & -0.00225 & & & -0.05965 \\
\hline & & & $(0.016)$ & & & $(0.043)$ \\
\hline Firm fix ed effects & NO & NO & NO & YES & YES & YES \\
\hline Firm size and age controls & YES & YES & YES & NO & NO & NO \\
\hline Country *Year fix ed effects & YES & YES & YES & YES & YES & YES \\
\hline Industry *Year fix ed effects & YES & YES & YES & YES & YES & YES \\
\hline Observ ations & 692,119 & 692,119 & 692,119 & 701,304 & 701,304 & 701,304 \\
\hline R2 & 0.103 & 0.103 & 0.103 & 0.819 & 0.819 & 0.819 \\
\hline
\end{tabular}

Note: Columns 1 to 3 correspond to a Neo-Schumpeterian growth model with productivity growth regressed on lagged productivity gap to the frontier (only lagged productivity is included here as the frontier is captured in the industry*year fixed effects). Columns 4 to 6 estimate the effect of the level of platform development on the level of firm productivity in the following year. $\triangle \mathrm{MFP}_{\mathrm{i}, \mathrm{t}}$ is the 1-year multifactor productivity growth of firm $i$ in year $t$, based on Solow residual estimations, and MFP $\mathrm{i}, \mathrm{t}$ is the level of multifactor productivity of firm $i$ in year $t$, using the same measure. The 3 platform variables correspond to the popularity of (i) all platforms, (ii) "aggregator" platforms (e.g. Booking.com, TheFork), (iii) "disruptor" platforms (e.g. Airbnb, Uber). Industry refers to 4-digit level NACE sectors, namely hotels (5510), restaurants (5610), taxi (4932), retail trade of books (4761), of toys (4765), of shoes (4772), of perfume and cosmetics (4775) and of watches and jewellery (4777). The sample covers BEL, DEU, ESP, FRA, GBR, HUN, ITA, POL, SWE, USA over 2004-2016. Robust standard errors are clustered by firm and by country-industry-year. *** denotes statistical significance at the $1 \%$ level, ${ }^{* *}$ significance at the $5 \%$ level, ${ }^{*}$ significance at the $10 \%$ level.

Source: OECD calculations based on ORBIS and Google Trends. 
Table B.2. Effect of online platforms on the productivity of existing service providers, robustness to different time lags

\begin{tabular}{|c|c|c|c|c|c|c|c|c|c|c|c|c|}
\hline \multirow[b]{2}{*}{ Dependent variable: } & (1) & (2) & (3) & (4) & (5) & (6) & (7) & (8) & (9) & (10) & (11) & (12) \\
\hline & \multicolumn{3}{|c|}{$\Delta M F P_{i, t}$ over 1 year } & \multicolumn{3}{|c|}{$\Delta M F P_{i, t}$ over 2 years } & \multicolumn{3}{|c|}{$\Delta M F P_{i, t}$ over 3 years } & \multicolumn{3}{|c|}{$\Delta M F P_{i, t}$ over 4 years } \\
\hline \multirow{2}{*}{ All platforms $s_{c, s, t-x}$} & $0.08193^{* * *}$ & & & $0.07508^{*}$ & & & 0.07474 & & & $0.10242^{*}$ & & \\
\hline & $(0.032)$ & & & $(0.040)$ & & & $(0.051)$ & & & $(0.060)$ & & \\
\hline \multirow[t]{2}{*}{ Aggregators $_{c, s, t-x}$} & & $0.10434^{* * *}$ & & & $0.10607^{* *}$ & & & $0.09839^{*}$ & & & $0.11249^{*}$ & \\
\hline & & $(0.032)$ & & & $(0.040)$ & & & $(0.053)$ & & & $(0.061)$ & \\
\hline \multirow[t]{2}{*}{ Disruptors $_{\mathrm{c}, \mathrm{s}, \mathrm{t}-\mathrm{x}}$} & & & 0.01966 & & & -0.03920 & & & -0.01754 & & & 0.07022 \\
\hline & & & $(0.041)$ & & & $(0.064)$ & & & $(0.089)$ & & & $(0.107)$ \\
\hline Firm fix ed effects & YES & YES & YES & YES & YES & YES & YES & YES & YES & YES & YES & YES \\
\hline Country ${ }^{*} Y e a r$ fix ed effects & YES & YES & YES & YES & YES & YES & YES & YES & YES & YES & YES & YES \\
\hline Industry ${ }^{*} Y e a r$ fix ed effects & YES & YES & YES & YES & YES & YES & YES & YES & YES & YES & YES & YES \\
\hline Observations & 701,304 & 701,304 & 701,304 & 553,243 & 553,243 & 553,243 & 443,346 & 443,346 & 443,346 & 353,566 & 353,566 & 353,566 \\
\hline $\mathrm{R} 2$ & 0.171 & 0.171 & 0.171 & 0.261 & 0.261 & 0.261 & 0.346 & 0.346 & 0.346 & 0.431 & 0.431 & 0.431 \\
\hline
\end{tabular}

Note: $\triangle \mathrm{MFP}$ is the cumulated multifactor productivity growth over respectively $1,2,3$ or 4 years of firm $i$ in year $t$, based on Solow residual estimations. Platform variables are lagged accordingly (e.g. by 3 years for the 3 -year change in productivity). The 3 platform variables correspond to the popularity of (i) all platforms, (ii) "aggregator" platforms (e.g. Booking.com, TheFork), (iii) "disruptor" platforms (e.g. Airbnb, Uber), using the a one year (columns 1-3) to four years (columns 10-12) time lag. Industry refers to 4-digit level NACE sectors, namely hotels (5510), restaurants (5610), taxi (4932), retail trade of books (4761), of toys (4765), of shoes (4772), of perfume and cosmetics (4775) and of watches and jewellery (4777). The sample covers BEL, DEU, ESP, FRA, GBR, HUN, ITA, POL, SWE, USA over 2004-2016. Country*Industry fixed effects are also captured by the firm fixed effects as these variables are firm-specific and time-invariant in the Orbis dataset. Robust standard errors are clustered by firm and by country-industry-year. $* * *$ denotes statistical significance at the $1 \%$ level, $* *$ significance at the $5 \%$ level, $*$ significance at the $10 \%$ level.

Source: OECD calculations based on ORBIS and Google Trends. 
Table B.3. Effect of online platforms on the productivity of existing service providers, robustness to controlling for overall demand in each country, industry and year

\begin{tabular}{|c|c|c|c|c|c|c|}
\hline & (1) & $(2)$ & (3) & (4) & (5) & (6) \\
\hline & \multicolumn{6}{|c|}{ Dependent variable: $\triangle M F P i, t$} \\
\hline \multirow[t]{2}{*}{ All platforms $\mathrm{c}_{\mathrm{c}, \mathrm{s}, \mathrm{t}-1}$} & $0.08141^{* *}$ & & & $0.07691^{* *}$ & & \\
\hline & $(0.032)$ & & & $(0.032)$ & & \\
\hline \multirow[t]{2}{*}{ Aggregators $_{\mathrm{c}, \mathrm{s}, \mathrm{t}-1}$} & & $0.10420^{\star \star *}$ & & & $0.09919^{* * *}$ & \\
\hline & & $(0.032)$ & & & $(0.032)$ & \\
\hline \multirow[t]{2}{*}{ Disruptors $_{\mathrm{c}, \mathrm{s}, \mathrm{t}-1}$} & & & 0.02027 & & & 0.01432 \\
\hline & & & $(0.041)$ & & & $(0.041)$ \\
\hline \multirow[t]{2}{*}{$\Delta$ Sectorlnterest $_{c, s, t}$} & 0.04990 & 0.05481 & 0.05767 & & & \\
\hline & $(0.071)$ & $(0.070)$ & $(0.071)$ & & & \\
\hline \multirow[t]{2}{*}{$\Delta$ Sectorlnterest $_{\mathrm{c}, \mathrm{s}, \mathrm{t}-1}$} & & & & 0.10272 & 0.09774 & $0.11807^{*}$ \\
\hline & & & & $(0.066)$ & $(0.066)$ & $(0.067)$ \\
\hline Firm fix ed effects & YES & YES & YES & YES & YES & YES \\
\hline Country *Year fix ed effects & YES & YES & YES & YES & YES & YES \\
\hline Industry ${ }^{*} Y$ ear fix ed effects & YES & YES & YES & YES & YES & YES \\
\hline Observations & 701,304 & 701,304 & 701,304 & 656,017 & 656,017 & 656,017 \\
\hline $\mathrm{R} 2$ & 0.171 & 0.171 & 0.171 & 0.175 & 0.175 & 0.175 \\
\hline
\end{tabular}

Note: The equation estimated corresponds to Equation 1. $\triangle \mathrm{MFP}$ is the 1-year multifactor productivity growth of firm $i$ in year $t$, based on Solow residual estimations. The three platform variables correspond to the popularity of (i) all platforms, (ii) "aggregator" platforms (e.g. Booking.com, TheFork), (iii) "disruptor" platforms (e.g. Airbnb, Uber). $\Delta$ SectorInterest is the first difference of a variable built from Google Trends, using the name of each sector as a keyword (e.g. "hotel", "restaurant") to proxy for overall demand in each country, industry and year. Industry refers to 4-digit level NACE sectors, namely hotels (5510), restaurants (5610), taxi (4932), retail trade of books (4761), of toys (4765), of shoes (4772), of perfume and cosmetics (4775) and of watches and jewellery (4777). The sample covers BEL, DEU, ESP, FRA, GBR, HUN, ITA, POL, SWE, USA over 2004-2016. Country*Industry fixed effects are also captured by the firm fixed effects as these variables are firm-specific and time-invariant in the Orbis dataset. Robust standard errors are clustered by firm and by country-industry-year. $* * *$ denotes statistical significance at the $1 \%$ level, ** significance at the $5 \%$ level, * significance at the $10 \%$ level.

Source: OECD calculations based on ORBIS and Google Trends. 
Table B.4. Effect of online platforms on the productivity of existing service providers, alternative productivity measures

\begin{tabular}{|c|c|c|c|c|c|c|c|c|c|}
\hline & (1) & (2) & (3) & (4) & (5) & (6) & (7) & (8) & (9) \\
\hline Dependent variable: & \multicolumn{3}{|c|}{$\Delta L P_{i, t}$} & \multicolumn{3}{|c|}{$\Delta M F P_{-} W_{i, t}$} & \multicolumn{3}{|c|}{$\Delta$ Mark-up corrected MFP $P_{i, t}$} \\
\hline \multirow[t]{2}{*}{ All platforms $s_{c, s, t-1}$} & $0.07784^{* *}$ & & & $0.07020^{* *}$ & & & $0.03737^{*}$ & & \\
\hline & $(0.034)$ & & & $(0.033)$ & & & $(0.020)$ & & \\
\hline \multirow[t]{2}{*}{ Aggregators $_{c, s, t-1}$} & & $0.09834^{* * *}$ & & & $0.09420^{* * *}$ & & & $0.03721^{*}$ & \\
\hline & & $(0.034)$ & & & $(0.033)$ & & & $(0.021)$ & \\
\hline \multirow[t]{2}{*}{ Disruptors $_{c, s, t-1}$} & & & 0.03684 & & & 0.02495 & & & 0.01854 \\
\hline & & & $(0.044)$ & & & $(0.043)$ & & & $(0.027)$ \\
\hline Firm fix ed effects & YES & YES & YES & YES & YES & YES & YES & YES & YES \\
\hline Country ${ }^{*}$ Year fix ed effects & YES & YES & YES & YES & YES & YES & YES & YES & YES \\
\hline Industry *Year fix ed effects & YES & YES & YES & YES & YES & YES & YES & YES & YES \\
\hline Observations & 702,847 & 702,847 & 702,847 & 703,940 & 703,940 & 703,940 & 490,830 & 490,830 & 490,830 \\
\hline R2 & 0.153 & 0.153 & 0.153 & 0.165 & 0.165 & 0.165 & 0.184 & 0.184 & 0.183 \\
\hline
\end{tabular}

Note: The equation estimated corresponds to Equation 1. $\Delta$ LP is labour productivity growth, based on value added and employment. MFP_W corresponds to the multifactor productivity based on Wooldridge estimation. Mark-up corrected MFP corresponds to a measure of multifactor productivity corrected for firm- and timevarying mark-ups, estimated by the De Loecker and Warzynski method. The three platform variables correspond to the popularity of (i) all platforms, (ii) "aggregator" platforms (e.g. Booking.com, TheFork), (iii) "disruptor" platforms (e.g. Airbnb, Uber). Industry refers to 4-digit level NACE sectors, namely hotels (5510), restaurants (5610), taxi (4932), retail trade of books (4761), of toys (4765), of shoes (4772), of perfume and cosmetics (4775) and of watches and jewellery (4777). The sample covers BEL, DEU, ESP, FRA, GBR, HUN, ITA, POL, SWE, USA over 2004-2016. Country*Industry fixed effects are also captured by the firm fixed effects as these variables are firm-specific and time-invariant in the Orbis dataset. Robust standard errors are clustered by firm and by country-industry-year. $* * *$ denotes statistical significance at the $1 \%$ level, ** significance at the $5 \%$ level, * significance at the $10 \%$ level.

Source: OECD calculations based on ORBIS and Google Trends. 
Table B.5. Effect of online platforms on the productivity of existing service providers, restricting the sample to five countries

\begin{tabular}{|c|c|c|c|}
\hline & (1) & (2) & (3) \\
\hline & \multicolumn{3}{|c|}{ Dependent variable: $\triangle M F P i, t$} \\
\hline \multirow[t]{2}{*}{ All platforms $s_{c, s, t-1}$} & $0.11262^{* * *}$ & & \\
\hline & $(0.038)$ & & \\
\hline \multirow[t]{2}{*}{ Aggregators $_{\mathrm{c}, \mathrm{s}, \mathrm{t}-1}$} & & $0.13220^{* * *}$ & \\
\hline & & $(0.037)$ & \\
\hline \multirow[t]{2}{*}{ Disruptors $_{c, s, t-1}$} & & & 0.03136 \\
\hline & & & $(0.046)$ \\
\hline Firm fixed effects & YES & YES & YES \\
\hline Country ${ }^{*} Y e a r$ fix ed effects & YES & YES & YES \\
\hline Industry *Year fix ed effects & YES & YES & YES \\
\hline Observations & 661,412 & 661,412 & 661,412 \\
\hline R2 & 0.169 & 0.169 & 0.169 \\
\hline
\end{tabular}

Note: The equation estimated corresponds to Equation 1. $\Delta \mathrm{MFP}$ is the 1-year multifactor productivity growth of firm $i$ in year $t$, based on Solow residual estimations. The 3 platform variables correspond to the popularity of (i) all platforms, (ii) "aggregator" platforms (e.g. Booking.com, TheFork), (iii) "disruptor" platforms (e.g. Airbnb, Uber). Industry refers to 4-digit level NACE sectors, namely hotels (5510), restaurants (5610), taxi (4932), retail trade of books (4761), of toys (4765), of shoes (4772), of perfume and cosmetics (4775) and of watches and jewellery (4777). The sample covers BEL, ESP, FRA, ITA, SWE (the sample countries with the best ORBIS coverage) over 2004-2016. Country*Industry fixed effects are also captured by the firm fixed effects as these variables are firm-specific and time-invariant in the Orbis dataset. Robust standard errors are clustered by firm and by country-industry-year. $* * *$ denotes statistical significance at the $1 \%$ level, ** significance at the $5 \%$ level, * significance at the $10 \%$ level.

Source: OECD calculations based on ORBIS and Google Trends.

Table B.6. Effect of online platforms on the productivity of existing service providers, detailed results by sector

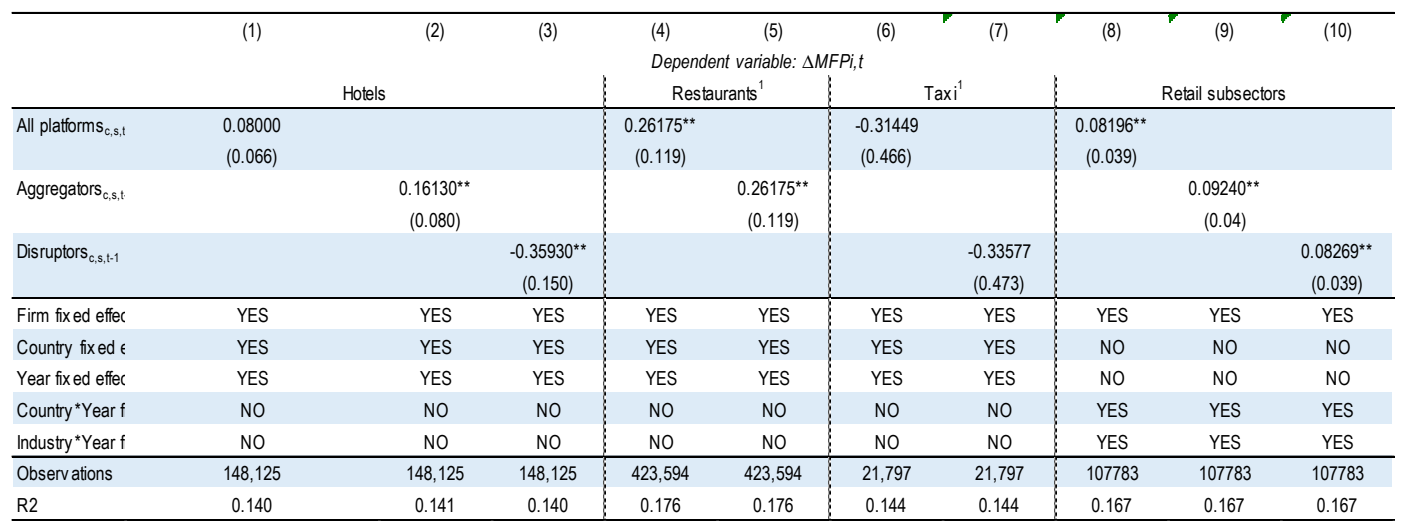

Note: Hotels refer to the NACE classification code 5510, restaurants, 5610, taxi, 4932, and retail subsectors $4761,4765,4772,4775$ and 4777 . Robust standard errors are clustered by firm and by country, industry and year. $* * *$ denotes statistical significance at the $1 \%$ level, $* *$ significance at the $5 \%$ level, $*$ significance at the $10 \%$ level

${ }^{1}$ All platforms in the restaurants sector are Aggregators, while Aggregators are absent in most countries in the taxi sector.

Source: OECD calculations based on ORBIS and Google Trends. 
Table B.7. Effect of online platforms on allocative efficiency, alternative productivity measures

\begin{tabular}{|c|c|c|c|c|c|c|c|c|c|}
\hline \multirow[b]{3}{*}{ Productivity measure: } & (1) & (2) & (3) & (4) & (5) & (6) & (7) & (8) & (9) \\
\hline & \multicolumn{9}{|c|}{ Dependent variable: $\Delta L i, t$} \\
\hline & \multicolumn{3}{|c|}{$L P_{i t}$} & \multicolumn{3}{|c|}{$\triangle M F P_{-} W_{i, t}$} & \multicolumn{3}{|c|}{$\Delta$ Mark-up corrected MFP ${ }_{i, t}$} \\
\hline & $\begin{array}{c}0.10884^{* \star \star} \\
(0.011)\end{array}$ & $\begin{array}{c}0.10852^{* * *} \\
(0.011)\end{array}$ & $\begin{array}{c}0.10586^{* * *} \\
(0.011)\end{array}$ & $\begin{array}{c}0.09455^{* * *} \\
(0.008)\end{array}$ & $\begin{array}{c}0.09433^{* * *} \\
(0.008)\end{array}$ & $\begin{array}{c}0.09145^{* * *} \\
(0.008)\end{array}$ & $\begin{array}{c}0.10413^{* * *} \\
(0.013)\end{array}$ & $\begin{array}{c}0.10418^{* * *} \\
(0.013)\end{array}$ & $\begin{array}{r}0.09953^{* *} \\
(0.013)\end{array}$ \\
\hline Productivity $_{i,-1-1}{ }^{*}$ All platforms $s_{c, s, t-1}$ & $\begin{array}{c}0.04294^{* * *} \\
(0.011)\end{array}$ & & & $\begin{array}{c}0.03652^{* * *} \\
(0.009)\end{array}$ & & & $\begin{array}{c}0.06860^{* * *} \\
(0.017)\end{array}$ & & \\
\hline Productivity $_{i,-1-1}{ }^{*}$ Aggregators $s_{c, s, t-1}$ & & $\begin{array}{c}0.05009^{* * *} \\
(0.014)\end{array}$ & & & $\begin{array}{r}0.04282^{* * *} \\
(0.011)\end{array}$ & & & $\begin{array}{r}0.08330^{* * *} \\
(0.020)\end{array}$ & \\
\hline Productivity $_{i,-1-1}{ }^{*}$ Disruptors $_{c, s, t-1}$ & & & $\begin{array}{l}0.00203 \\
(0.016) \\
\end{array}$ & & & $\begin{array}{c}-0.00131 \\
(0.013) \\
\end{array}$ & & & $\begin{array}{r}0.04125^{* *} \\
(0.021) \\
\end{array}$ \\
\hline Productivity $y_{i,-1}$ * Sector dummies & YES & YES & YES & YES & YES & YES & YES & YES & YES \\
\hline Productivity $y_{i,-1}{ }^{*}$ Time dummies & YES & YES & YES & YES & YES & YES & YES & YES & YES \\
\hline Firm Age and Size Controls & YES & YES & YES & YES & YES & YES & YES & YES & YES \\
\hline Country ${ }^{*}$ Industry ${ }^{*}$ Year fix ed effects & YES & YES & YES & YES & YES & YES & YES & YES & YES \\
\hline Observations & 704,991 & 704,991 & 704,991 & 697,994 & 697,994 & 697,994 & 521,164 & 521,164 & 521,164 \\
\hline R2 & 0.064 & 0.064 & 0.064 & 0.048 & 0.048 & 0.048 & 0.053 & 0.053 & 0.053 \\
\hline
\end{tabular}

Note: The equation estimated corresponds to Equation 2. $\Delta \mathrm{L}$ denotes employment growth at the firm-level. LP denotes firm's labour productivity, based on value added and employment. MFP_W corresponds to the multifactor productivity based on Wooldridge estimation. Mark-up corrected MFP corresponds to a measure of multifactor productivity corrected for firm- and time-varying mark-ups, estimated by the De Loecker and Warzynski method. All productivity variables are defined as the deviation from country-industry-year mean. The 3 platform variables correspond to the popularity of (i) all platforms, (ii) "aggregator" platforms (e.g. Booking.com, TheFork), (iii) "disruptor" platforms (e.g. Airbnb, Uber). Industry refers to 4-digit level NACE sectors, namely hotels (5510), restaurants (5610), taxi (4932), retail trade of books (4761), of toys (4765), of shoes (4772), of perfume and cosmetics (4775) and of watches and jewellery (4777). The sample covers BEL, DEU, ESP, FRA, GBR, HUN, ITA, POL, SWE, USA over 2004-2016. Robust standard errors are clustered by firm and by country-industry-year. ${ }^{* * *}$ denotes statistical significance at the $1 \%$ level, $* *$ significance at the $5 \%$ level, * significance at the $10 \%$ level.

Source: OECD calculations based on ORBIS and Google Trends. 
Table B.8. Effect of online platforms on allocative efficiency, restricting the sample to five countries

\begin{tabular}{|c|c|c|c|}
\hline & (1) & (2) & (3) \\
\hline $\mathrm{MFP}_{\mathrm{i}, \mathrm{t}-1}$ & $\begin{array}{c}0.03465^{* * *} \\
(0.009)\end{array}$ & $\begin{array}{c}0.03658^{* * *} \\
(0.009)\end{array}$ & $\begin{array}{c}0.03124^{* * *} \\
(0.009)\end{array}$ \\
\hline $\mathrm{MFP}_{\mathrm{i}, \mathrm{t}-1}{ }^{*}$ All platforms $\mathrm{c}_{\mathrm{c}, \mathrm{s}, \mathrm{t}-1}$ & $\begin{array}{c}0.03827^{* * *} \\
(0.012)\end{array}$ & & \\
\hline $\mathrm{MFP}_{\mathrm{i}, \mathrm{t}-1}{ }^{*}$ Aggregators ${ }_{\mathrm{c}, \mathrm{s}, \mathrm{t}-1}$ & & $\begin{array}{c}0.04771^{* * *} \\
(0.014)\end{array}$ & \\
\hline $\mathrm{MFP}_{\mathrm{i}, \mathrm{t}-1}{ }^{*}$ Disruptors $\mathrm{c}_{\mathrm{c}, \mathrm{s}, \mathrm{t}-1}$ & & & $\begin{array}{c}0.00904 \\
(0.015) \\
\end{array}$ \\
\hline $\mathrm{MFP}_{\mathrm{i},-1-1} *$ Sector dummies & YES & YES & YES \\
\hline $\mathrm{MFP}_{\mathrm{i}, \mathrm{t}-1}{ }^{*}$ Time dummies & YES & YES & YES \\
\hline Firm Age and Size Controls & YES & YES & YES \\
\hline Country ${ }^{*}$ Industry ${ }^{*}$ Year fix ed effects & YES & YES & YES \\
\hline Observations & 652,240 & 652,240 & 652,240 \\
\hline R2 & 0.029 & 0.029 & 0.028 \\
\hline
\end{tabular}

Note: The equation estimated corresponds to Equation 2. $\Delta \mathrm{L}$ denotes the 1-year employment growth at the firmlevel. MFP denotes firm's multifactor productivity, based on Solow residual estimations, defined as the deviation from country-industry-year mean. The 3 platform variables correspond to the popularity of (i) all platforms, (ii) "aggregator" platforms (e.g. Booking.com, TheFork), (iii) "disruptor" platforms (e.g. Airbnb, Uber). Industry refers to 4-digit level NACE sectors, namely hotels (5510), restaurants (5610), taxi (4932), retail trade of books (4761), of toys (4765), of shoes (4772), of perfume and cosmetics (4775) and of watches and jewellery (4777). The sample covers BEL, ESP, FRA, ITA, SWE over 2004-2016. Robust standard errors are clustered by firm and by country-industry-year. $* * *$ denotes statistical significance at the $1 \%$ level, $* *$ significance at the $5 \%$ level, * significance at the $10 \%$ level.

Source: OECD calculations based on ORBIS and Google Trends. 
Table B.9. Effect of online platforms on allocative efficiency, detailed results by sector

\begin{tabular}{|c|c|c|c|c|c|c|c|c|c|c|}
\hline & (1) & (2) & (3) & (4) & (5) & (6) & (8) & (9) & (10) & (11) \\
\hline & \multicolumn{10}{|c|}{ Dependent variable: $\Delta L i, t$} \\
\hline & \multicolumn{3}{|c|}{ Hotels } & \multicolumn{2}{|c|}{ Restaurants $^{1}$} & \multicolumn{2}{|c|}{$\operatorname{Taxi}^{1}$} & \multicolumn{3}{|c|}{ Retail subsectors } \\
\hline $\operatorname{MFP}_{i,-1}$ & $\begin{array}{c}0.02572^{\star *} \\
(0.013)\end{array}$ & $\begin{array}{c}0.02522^{*} \\
(0.013)\end{array}$ & $\begin{array}{c}0.02842^{\star \star} \\
(0.013)\end{array}$ & $\begin{array}{c}0.04720^{* * \star} \\
(0.012)\end{array}$ & $\begin{array}{c}0.04720^{* \star *} \\
(0.012)\end{array}$ & $\begin{array}{c}0.03886^{* *} \\
(0.017)\end{array}$ & $\begin{array}{c}.03953^{* *} \\
(0.017)\end{array}$ & $\begin{array}{c}0.02785^{* * *} \\
(0.005)\end{array}$ & $\begin{array}{c}0.02752^{* * *} \\
(0.005)\end{array}$ & $\begin{array}{c}0.02785^{* * *} \\
(0.005)\end{array}$ \\
\hline $\operatorname{MFP}_{i, t-1}{ }^{*}$ All platforms s, $s_{, s, t-1}$ & $\begin{array}{c}0.05716^{* * *} \\
(0.015)\end{array}$ & & & $\begin{array}{c}0.12983^{* \star *} \\
(0.045)\end{array}$ & & $\begin{array}{c}-0.15721 \\
(0.395)\end{array}$ & & $\begin{array}{c}-0.00582 \\
(0.009)\end{array}$ & & \\
\hline $\mathrm{MFP}_{\mathrm{i},-1{ }^{*}}$ Aggregators $\mathrm{c}_{\mathrm{c}, \mathrm{s},-1}$ & & $\begin{array}{c}0.06810^{* \star \star} \\
(0.017)\end{array}$ & & & $\begin{array}{c}0.12983^{\star \star \star} \\
(0.045)\end{array}$ & & & & $\begin{array}{c}-0.00746 \\
(0.010)\end{array}$ & \\
\hline $\operatorname{MFP}_{i, t-1}{ }^{*}$ Disruptors $_{c, s, t-1}$ & & & $\begin{array}{l}0.10893 \\
(0.086) \\
\end{array}$ & & & & $\begin{array}{c}-0.19592 \\
(0.409) \\
\end{array}$ & & & $\begin{array}{c}-0.00580 \\
(0.009) \\
\end{array}$ \\
\hline $\mathrm{MFP}_{\mathrm{i},-1-1}{ }^{*}$ Sector dummies & NO & NO & NO & NO & NO & NO & NO & NO & NO & NO \\
\hline $\mathrm{MFP}_{\mathrm{i}, t-1}{ }^{*}$ Time dummies & YES & YES & YES & YES & YES & YES & YES & YES & YES & YES \\
\hline Firm Age and Size Controls & YES & YES & YES & YES & YES & YES & YES & YES & YES & YES \\
\hline Country ${ }^{*} Y e a r$ fix ed effects & YES & YES & YES & YES & YES & YES & YES & NO & NO & NO \\
\hline Country ${ }^{*}$ Industry ${ }^{*} Y e a r$ fixed effects & NO & NO & NO & NO & NO & NO & NO & YES & YES & YES \\
\hline Observations & 143,578 & 143,578 & 143,578 & 422,120 & 422,120 & 21,310 & 21,310 & 105,087 & 105,087 & 105,087 \\
\hline R2 & 0.0263 & 0.0264 & 0.0260 & 0.0297 & 0.0297 & 0.0247 & 0.0247 & 0.0222 & 0.0222 & 0.0222 \\
\hline
\end{tabular}

Note: Hotels refer to the NACE classification code 5510, restaurants, 5610, taxi, 4932, and retail subsectors $4761,4765,4772,4775$ and 4777 . Robust standard errors are clustered by firm and by country, industry and year. $* * *$ denotes statistical significance at the $1 \%$ level, $* *$ significance at the $5 \%$ level, * significance at the $10 \%$ level

${ }^{1}$ All platforms in the restaurants sector are Aggregators, while Aggregators are absent in most countries in the taxi sector.

Source: OECD calculations based on ORBIS and Google Trends. 
Table B.10. Effect of online platforms on the productivity of existing service providers, effect of competition on the platform market, alternative concentration variables

\begin{tabular}{|c|c|c|c|c|c|c|c|}
\hline & (1) & (2) & $(3)$ & (4) & (5) & (6) & (7) \\
\hline \multicolumn{8}{|c|}{ Dependent variable: $\triangle M F P i, t$} \\
\hline Concentration variable: & $\begin{array}{c}\text { Market share of the } \\
\text { largest platform }\end{array}$ & \multicolumn{3}{|c|}{ Concentration above 75 th percentile } & \multicolumn{3}{|c|}{ Concentration above median } \\
\hline Persistence variable: & & & $\begin{array}{l}2 \text { year- } \\
\text { persistence }\end{array}$ & $\begin{array}{l}1 \text { year- } \\
\text { persistence }\end{array}$ & & $\begin{array}{l}2 \text { year- } \\
\text { persistence }\end{array}$ & $\begin{array}{l}1 \text { year- } \\
\text { persistence }\end{array}$ \\
\hline Aggregators $_{c, s, t-1}$ & $\begin{array}{c}0.10022^{* * *} \\
(0.032)\end{array}$ & $\begin{array}{c}0.11330^{* * *} \\
(0.032)\end{array}$ & $\begin{array}{c}0.11088^{* * *} \\
(0.034)\end{array}$ & $\begin{array}{c}0.11115^{\star * *} \\
(0.033)\end{array}$ & $\begin{array}{c}0.13642^{* * *} \\
(0.035)\end{array}$ & $\begin{array}{c}0.11958^{* * *} \\
(0.035)\end{array}$ & $\begin{array}{c}0.13246^{\star * *} \\
(0.036)\end{array}$ \\
\hline Concentrated $_{\mathrm{c}, \mathrm{s}, \mathrm{t}-1^{*}}$ & $\begin{array}{c}0.01503 \\
(0.009)\end{array}$ & $\begin{array}{c}-0.00245 \\
(0.006)\end{array}$ & & & $\begin{array}{c}0.00215 \\
(0.004)\end{array}$ & & \\
\hline Aggregators ${ }^{*}$ Concentrated $\mathrm{c}_{\mathrm{c}, \mathrm{s}, \mathrm{t}-\mathrm{t}^{*}}$ & $\begin{array}{c}-0.16212^{* *} \\
(0.066)\end{array}$ & $\begin{array}{c}-0.14457^{\star * *} \\
(0.051)\end{array}$ & & & $\begin{array}{c}-0.08236^{\star * *} \\
(0.030)\end{array}$ & & \\
\hline Concentrated ${ }^{*}$ Persistent $t_{c, s, t-1-t^{*}}$ & & & $\begin{array}{c}-0.00224 \\
(0.007)\end{array}$ & $\begin{array}{c}-0.00265 \\
(0.006)\end{array}$ & & $\begin{array}{c}0.00136 \\
(0.005)\end{array}$ & $\begin{array}{l}0.00076 \\
(0.004)\end{array}$ \\
\hline Concentrated ${ }^{*}$ NonPersistent $t_{\mathrm{c}, \mathrm{s}, \mathrm{t}^{-1 *}}$ & & & $\begin{array}{c}-0.01127 \\
(0.013)\end{array}$ & $\begin{array}{c}-0.00708 \\
(0.016)\end{array}$ & & $\begin{array}{l}0.01006 \\
(0.008)\end{array}$ & $\begin{array}{c}0.01638 \\
(0.012)\end{array}$ \\
\hline Aggregators ${ }^{*}$ Concentrated ${ }^{\star}$ Persistent $t_{c, s, t-1{ }^{*}}$ & & & $\begin{array}{c}-0.13660^{* *} \\
(0.063)\end{array}$ & $\begin{array}{c}-0.13326^{\star *} \\
(0.057)\end{array}$ & & $\begin{array}{c}-0.08842^{* * *} \\
(0.031)\end{array}$ & $\begin{array}{c}-0.08568^{* * *} \\
(0.030)\end{array}$ \\
\hline Aggregators ${ }^{*}$ Concentrated ${ }^{*}$ NonPersistent $t_{c, s, t-1-^{*}}$ & & & $\begin{array}{c}-0.21393 \\
(0.148)\end{array}$ & $\begin{array}{c}-0.06154 \\
(0.142) \\
\end{array}$ & & $\begin{array}{c}-0.02390 \\
(0.065) \\
\end{array}$ & $\begin{array}{c}0.07661 \\
(0.127) \\
\end{array}$ \\
\hline Firm fix ed effects & YES & YES & YES & YES & YES & YES & YES \\
\hline Country ${ }^{*}$ Year fix ed effects & YES & YES & YES & YES & YES & YES & YES \\
\hline Industry *Year fix ed effects & YES & YES & YES & YES & YES & YES & YES \\
\hline Observations & 701,304 & 701,304 & 610,287 & 656,017 & 701,304 & 610,287 & 656,017 \\
\hline R2 & 0.171 & 0.171 & 0.181 & 0.175 & 0.171 & 0.181 & 0.175 \\
\hline
\end{tabular}

Note: The equation estimated in columns 1, 2 and 5 corresponds to Equation 3, where the platform variable (Aggregators) corresponds to the popularity (as measured by Google Trends) of "aggregator" platforms in each country-industry-year. The policy variable is the variable Concentrated, which is the market share of the largest platform (proxied from Google Trends data) in column 1, or a dummy taking the value one when this market share is above the sample $75^{\text {th }}$ percentile (in column 2 ), or above the median (in column 5 ). In columns $3,4,6$, 7 , the concentration variable is interacted with a persistence dummy variable, taking the value of one when the largest platform in a country and industry was already the largest in the previous (columns 4,7 ) or the two previous (columns 3,6) years . $\triangle \mathrm{MFP}$ is the 1-year multifactor productivity growth of firm $i$ in year $t$, based on Solow residual estimations. Industry refers to 4-digit level NACE sectors, namely hotels (5510), restaurants (5610), taxi (4932), retail trade of books (4761), of toys (4765), of shoes (4772), of perfume and cosmetics (4775) and of watches and jewellery (4777). The sample covers BEL, DEU, ESP, FRA, GBR, HUN, ITA, POL, SWE, USA over 2004-2016. Robust standard errors are clustered by firm and by country-industry-year. *** denotes statistical significance at the $1 \%$ level, ${ }^{* *}$ significance at the $5 \%$ level, * significance at the $10 \%$ level. Source: OECD calculations based on Orbis and Google Trends. 